CARACTERISTICAS DE HISTORIA DE VIDA Y PATRONES DE ABUNDANCIA DE Mugil curema

Valenciennes 1836 EN LA LAGUNA DE PUEBLO VIEJO, VERACRUZ .

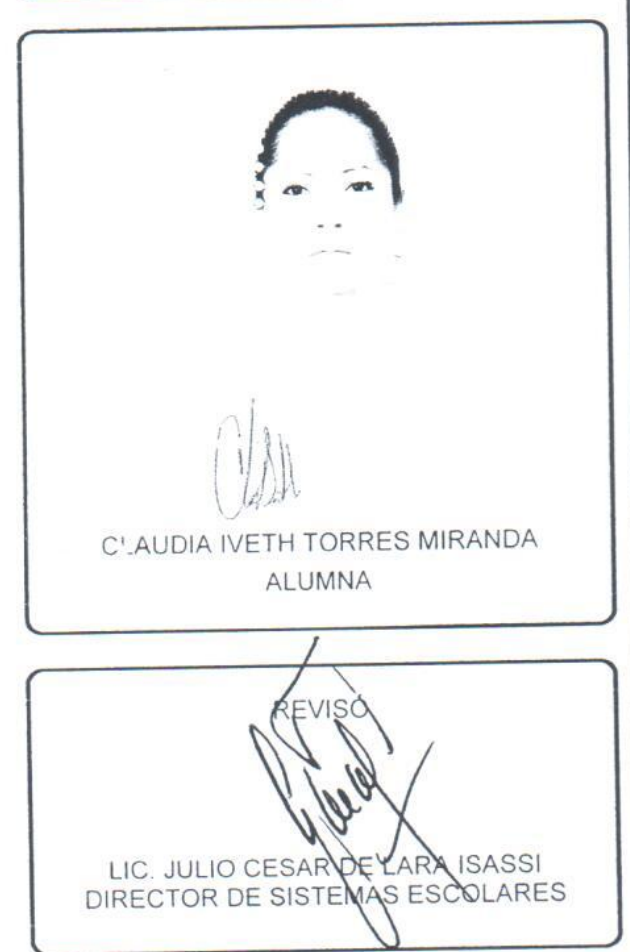

En México, D.F., se presentaron a las 11:00 horas del día 19 del mes de abril del año 2012 en la Unidad Iztapalapa de la Universidad Autónoma Metropolitana, los suscritos miembros del jurado:

M. EN B. MARIA DEL ROCIO ZARATE HERNANDEZ

M. EN C. JOSE ALBERTO MONTOYA MARQUEZ

M. EN C. ERNESTO MENDOZA VALLEJO

DR. ISAIAS HAZARMABETH SALGADO UGARTE
Bajo la Presidencia de la primera y con carácter de Secretario el último, se reunieron para proceder al Examen de Grado cuya denominación aparece al margen, para la obtención del grado de:

MAESTRA EN BIOLOGIA

DE: CLAUDIA IVETH TORRES MIRANDA

y de acuerdo con el artículo 78 fracción III del Reglamento de Estudios Superiores de la Universidad Autónoma Metropolitana, los miembros del jurado resolvieron:
Acto continuo, la presidenta del jurado comunicó a la interesada el resultado de la evaluación y, en caso aprobatorio, le fue tomada la protesta.

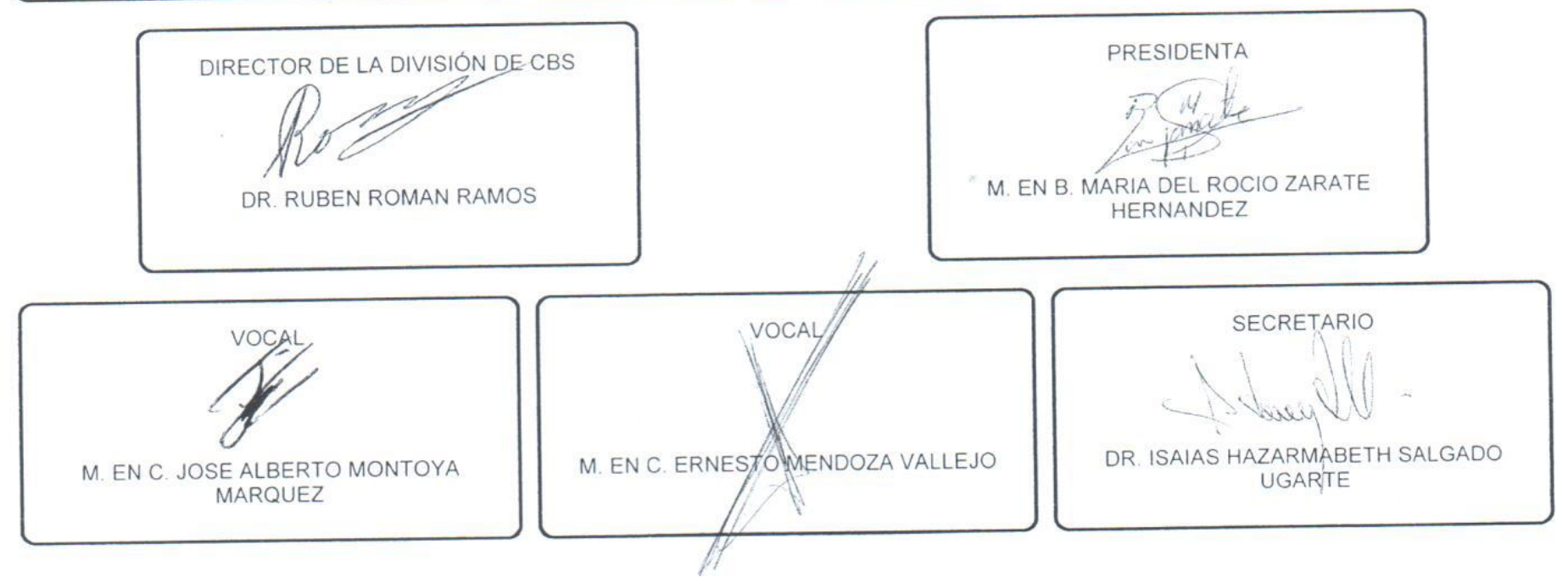




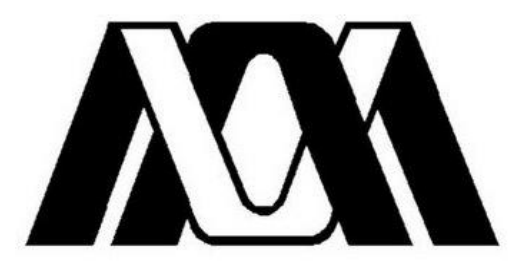

Casa abierta al tiempo

UNIVERSIDAD AUTÓNOMA METROPOLITANA

Iztapalapa

\title{
CARACTERÍSTICAS DE HISTORIA DE VIDA Y PATRONES DE ABUNDANCIA \\ RELATIVA DE Mugil curema Valenciennes, 1836 EN LA LAGUNA DE PUEBLO \\ VIEJO, VERACRUZ
}

\author{
TESIS \\ Que para obtener el grado de \\ Maestra en Biología \\ PRESENTA \\ Claudia Iveth Torres Miranda \\ DIRECTOR
}

DR. Manuel Castillo Rivera 
"La Maestría en Biología de la Universidad Autónoma Metropolitana pertenece al Padrón de Postgrados de Excelencia del CONACyT".

La presente tesis se desarrolló en el Laboratorio de Peces del Departamento de Biología, de la Universidad Autónoma Metropolitana, Unidad Iztapalapa, dentro del Proyecto de Investigación "Ecología de poblaciones y comunidades de peces del Golfo de México", el cual contó con el financiamiento de la Universidad Autónoma Metropolitana. 


$$
\begin{gathered}
\text { El jurado designado por la } \\
\text { División de Ciencias Biológicas y de la Salud } \\
\text { de la Unidad Iztapalapa aprobó la tesis que presentó }
\end{gathered}
$$

\title{
Claudia Iveth Torres Miranda
}

\author{
El día 19 de Abril del año de 2012
}

\section{Comité Tutoral}

Tutor: Dr. Manuel A. Castillo Rivera

Asesora: M. en C. Rocío Zárate Hernández

Asesor: Dr. Isaías Salgado Ugarte

Sinodal: M. en C. José Alberto Montoya Márquez

Sinodal: M. en C. Ernesto Mendoza Vallejo 


\section{DEDICATORIA}

A mis padres: Gelacio Torres Castillo y Ma. Isabel Miranda por su apoyo, paciencia, cariño y por el ejemplo de luchar hasta el último momento.

A mis hermanos

Antonio, Cesar, Isabel, Oscar y Daniel

por toda su comprensión y apoyo que me han brindado en los momentos mas difíciles de mi vida.

A mis sobrinos

Hadi y Said

Por todos los momentos gratos que hemos pasado y el cariño que me han brindado.

A Jorge

Por la paciencia que me tiene y por todos los momentos que hemos compartido juntos 


\section{AGRADECIMIENTOS}

Agradezco al Consejo Nacional de Ciencia y Tecnología (CONACyT) por la beca otorgada para la realización de mis estudios de Maestría.

Al Dr. Manuel Castillo, por la dirección y asesoría del presente trabajo por su apoyo durante el desarrollo del proyecto.

A la M. en B. Roció Zarate por sus valiosos comentarios, consejos, criticas y sugerencias que contribuyeron a enriquecer este trabajo. Además de su apoyo incondicional durante los dos años del posgrado.

Al M. C. Alberto Montoya y al Dr. Isaías Salgado (por sus enseñanzas de los EDKs) su tiempo, las facilidades y ayuda para el desarrollo de la parte de la determinación de la edad de este trabajo y por aceptar ser mis sinodales, así como por el animo a continuar aun en los días difíciles de este periodo, gracias por su amistad.

Al Dr. Ernestro Vallejo, por su participación como sinodal de mi examen de grado

Al Dr. Kovelkowsky por su ayuda en la identificación taxonómica de la especie $M$. curema.

Agradezco a la Universidad Autónoma Metropolitana-Iztapalapa por mi formación académica, y a la Coordinación del Posgrado por brindarme su apoyo económico. Especialmente al Dr. Alejandro Zavala y Dr. Abel Senties por todo el apoyo brindado durante el proyecto.

A los profesores amigos y compañeros de la UMAR Puerto Ángel Oaxaca, por los estímulos brindados durante mi estancia. A mis amigos y compañeros de la maestría Sayonara Pineda, Dora Carreón Paulina Gaby Ana Lidia, Alejandro Flores, Jiro 
Matsumoto por su mistad y las cosas que hemos compartido., especialmente a Esperanza Córdoba quien siempre estuvo para brindarme su apoyo en los momentos mas difíciles 


\section{RESUMEN}

Con la finalidad de obtener información de la distribución, abundancia, edad crecimiento y reproducción de la lebrancha, Mugil curema, en la Laguna de Pueblo Viejo, Veracruz, se efectuaron muestreos bimestrales, durante un año, con recolectas cada dos horas en 12 ciclos nictímeros, en dos diferentes tipos de hábitat, uno con vegetación sumergida (CVS) y otro sin este tipo de vegetación (SVS).Durante este estudio se capturaron 1, 149 individuos. Espacialmente, se capturó un mayor número de individuos en el hábitat CVS $(P=0.035)$. La talla promedio en el hábitat SVS ( $\bar{x}=62.68 \mathrm{~mm}$ ) fue significativamente mayor que en el hábitat CVS ( $\bar{x}=50.28$ ), lo cual puede relacionarse con el hecho de que los ambientes con vegetación representan zonas de protección y crianza para individuos juveniles. Analizando el crecimiento de los individuos en ambos hábitat se encontró un intervalo de talla de 19 a $221 \mathrm{~mm}$ con valores modales entre $22-28 \mathrm{~mm}, 37-50 \mathrm{~mm}$ y $90 \mathrm{~mm}$ siendo poco comunes individuos con tallas mayores a los $160 \mathrm{~mm}$ Para el estudio de edad se procesaron otolitos de 85 individuos, las estructuras se prepararon y examinaron por técnicas diferentes pero la evidencia de los anillos no fueron observados claramente De acuerdo con estas observaciones y tomando en cuenta el análisis de las tallas que presentan los individuos (para ambos hábitat) el $99.8 \%$ de los individuos capturados fue menor o igual a los $200 \mathrm{~mm}$ de longitud patrón (LP), por lo que se puede considerar que la mayoría de los individuos colectados tiene menos de un año de vida. Estacionalmente, la abundancia presentó un pulso importante en el mes de enero $(P=0.003)$, el cual estuvo dominado por individuos pequeños, lo que implica que durante este mes, existe un importante pulso de reclutamiento. y de acuerdo al método que aplica el programa de ELEFAN I, se aprecia dicha cohorte que inicia de enero hasta julio, el análisis de los datos, proporcionó una estimación de $L^{\infty}$ de $320 \mathrm{~mm}$. Mediante el uso de la distribución mensual de tallas y los EDKs se observa la presencia de otras dos cohortes en el mes de septiembre 89, mayo 90 además de la de enero, el seguimiento del valor de las modas de estas cohortes presento un ritmo de crecimiento en promedio total de $21 \mathrm{~mm}$ por mes. A nivel nictímero, la abundancia generalmente fue mayor durante el día (14:00-18:00), aunque sin mostrar diferencias significativas. En el hábitat CVS, durante el día predominaron individuos de talla menor, lo que podría relacionarse con estrategias de alimentación y de evasión de depredadores. La abundancia de esta especie se relaciona además con altas salinidades y con temperaturas bajas (mayores abundancias a $20^{\circ} \mathrm{C}$ ).Para los aspectos reproductivos los valores del índice gonadosamatico (IGS) fueron muy bajos, lo que explica en gran parte que la población de esta especie, está constituida por individuos juveniles, en fases tempranas de maduración además no se observó un periodo de reproducción bien definido debido a que no se encontraron gónadas categorizadas como maduras, sin embargo se propuso documentar la periodicidad de reproducción acuerdo con los meses que se detectaron como periodos de reclutamiento, respecto a lo anterior la reproducción de la especie podría ocurrir dentro de los periodos de diciembre-enero, marzo-abril y julio-septiembre. 


\section{ABSTRACT}

With the purpose of this work is getting information about distribution, abundance, age, growth and reproduction of lebrancha, Mullet curema, bimonthly samples were taken during one year in Lagoon of Pueblo Viejo, Veracruz, by making gatherings each two hours into 12 nictímeros cycles, All this into two different kinds of habitats, one of then was made with submerged vegetation (WSV) and the other without this kind of submerged vegetation (WOSV). During this study they were captured 1, 149 individuals. Specially a big amount individuals in the habitat WSV ( $P=0.035$ was captured). The average size in the habitat WOSV ( $\bar{x}=62.68 \mathrm{~mm}$ ) was significantly bigger that in the habitat WSV ( $\bar{x}=50.28)$, can be related to the fact that the habitat with vegetation represent protection areas and upbringing for young individuals. By analyzing the growth of the individuals in both habitats, it was found an interval of size from 19 to $221 \mathrm{~mm}$ with model values between $22-28 \mathrm{~mm}, 37-50 \mathrm{~mm}$ and $90 \mathrm{~mm}$ been less common individuals with sizes bigger than $160 \mathrm{~mm}$. For the age study were processed otoliths of 85 individuals, the structures were prepared and examined by different techniques but the evidence of the rings were not clearly observed. According to this observations and based on the size analysis showed by the individuals (in both habitats), $99.8 \%$ of the catched individuals were smaller or equal to $200 \mathrm{~mm}$ of pattern longitude (LP), for which we can consider that most of the gathered individuals are less than a year of life. Seasonally, abundance showed an important pulse of recruitment on January $(P=0.003)$, which was dominated by small individuals, this implies that during this month, exists an important pulse of recruitment. According to the method applied by ELEFAN I program, we could see such cohort it begins through January to July, the analysis of the data, provide an estimate of $L \infty$ of $320 \mathrm{~mm}$ of length. Through use of the monthly distribution of sizes and the EDKs is observed the presence of two different cohorts during September 89, May 90 and January, the fallowing of the mode value presents of growth on the average total of $21 \mathrm{~mm}$ for month. At a level nictímero, the abundance was generally bigger during the day (14:00-18:00), although without showing significant differences. In the habitat CVS, smaller size individuals during the day prevailed, which can be related to feed strategies and evasion of depredators. The abundance of this specie is related to high salinities and low temperatures (bigger abundances to $20^{\circ} \mathrm{C}$ ). For reproductive aspects the values of the gonadosamatic index (IGS) were very low, which explains that the population of this specie, it is constitute by juvenile individuals, in early phases of maturity. Besides it did not observed a well-defined period because they were not found gonads categorized as mature organism, nevertheless, it was proposed to document the periodicity of reproduction according to the months detected as a recruiting periods, according to the before explanation the reproduction of the specie might occur into the fallowing periods from December-January, MarchApril and July-September. 


\section{ÍNDICE GENERAL}

421 Muestreo y preservación de material

$\begin{array}{llll}4 & 2 & 2 & \text { Variables ambientales }\end{array}$

43 BIOMETRÍA

44 DISTRIBUCIÓN ESPACIO-TEMPORAL

45 DISTRIBUCIÓN Y ABUNDANCIA

$\begin{array}{llll}4 & 5 & 1 & \text { Influencia de las variables ambientales sobre la abundancia }\end{array}$

46 VARIACIÓN ESPACIO-TEMPORAL EN LA ESTRUCTURA DE LAS TALLAS

$\begin{array}{llll}4 & 6 & 1 & \text { Variaciones espaciales en la estructura de tallas }\end{array}$

$\begin{array}{llll}4 & 6 & 2 & \text { Variaciones estacionales en la estructura de tallas }\end{array}$

$\begin{array}{llll}4 & 6 & 3 & \text { Variaciones nictĺmeras en la estructura de tallas }\end{array}$

47 GRUPOS DE EDAD (COHORTES) Y CRECIMIENTO

471 Determinación de la edad (Método directo)

$\begin{array}{lllll}4 & 7 & 1 & 1 & \text { Selección de otolitos }\end{array}$

$\begin{array}{lllll}4 & 7 & 1 & 2 & \text { Extracción de otolitos }\end{array}$ 
$\begin{array}{lllll}4 & 7 & 1 & 3 & \text { Montado y pulido de otolitos }\end{array}$

$\begin{array}{lllll}4 & 7 & 1 & 4 & \text { Relación longitud patrón de los organismos-medidas del otolito }\end{array}$

$\begin{array}{lllll}4 & 7 & 1 & 5 & \text { Relación longitud patrón-peso del pez }\end{array}$

48 Distribución de frecuencias de tallas (Método indirecto)

49 ASPECTOS REPRODUCTIVOS

$\begin{array}{llll}4 & 9 & 1 & \text { Análisis gonádico }\end{array}$

5

ANÁLISIS ESTADÍSTICO

6

RESULTADOS

$6 \quad 1$

DISTRIBUCIÓN Y ABUNDANCIA

Análisis espacial

Análisis estacional

Análisis nictímero

Influencia de las variables ambientales sobre la abundancia

62 VARIACIÓN ESPACIO-TEMPORAL EN LA ESTRUCTURA DE LAS TALLAS

Variaciones espaciales en la estructura de tallas

Variaciones estacionales en la estructura de tallas

Variaciones nictímeras en la estructura de tallas

63 DETERMINACIÓN DE LA EDAD (MÉTODO DIRECTO)

$\begin{array}{llll}6 & 3 & 1 & \text { Selección y extracción de otolitos }\end{array}$

$\begin{array}{llll}6 & 3 & 2 & \text { Descripción del otolito }\end{array}$

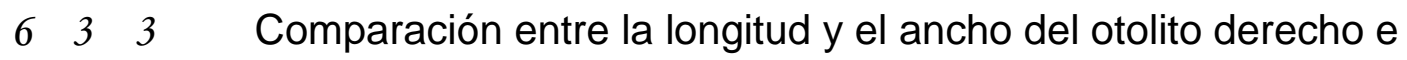
izquierdo

$\begin{array}{llll}6 & 3 & 4 & \text { Relación longitud patrón-peso }\end{array}$ 
$\begin{array}{llll}6 & 3 & 5 & \text { Relación longitud patrón (LP)- longitud del otolito }\end{array}$

$\begin{array}{llll}6 & 3 & 6 & \text { Relación longitud patrón (LP)- ancho del otolito }\end{array}$

64 DISTRIBUCIÓN DE FRECUENCIAS DE TALLAS (MÉTODO INDIRECTO)

$\begin{array}{llll}6 & 4 & 1 & \text { Análisis de la estructura de talla }\end{array}$

$\begin{array}{lllll}6 & 4 & 1 & 1 & \text { Análisis espacial }\end{array}$

$\begin{array}{lllll}6 & 4 & 1 & 2 & \text { Análisis estacional }\end{array}$

$\begin{array}{lllll}6 & 4 & 1 & 3 & \text { Análisis nictímero }\end{array}$

65 ASPECTOS REPRODUCTIVOS

$\begin{array}{llll}6 & 5 & 1 & \text { Análisis gonádico }\end{array}$

DISCUSIÓN

DISTRIBUCIÓN Y ABUNDANCIA

Análisis espacial

Análisis estacional

Análisis nictímero

VARIACIÓN ESPACIO-TEMPORAL EN LA ESTRUCTURA DE LAS TALLAS

Variaciones espaciales en la estructura de tallas

Variaciones estacionales en la estructura de tallas

Variaciones nictímeras en la estructura de tallas

DETERMINACIÓN DE LA EDAD (MÉTODO DIRECTO)

DISTRIBUCIÓN DE FRECUENCIAS DE TALLAS (MÉTODO INDIRECTO)

Análisis espacial

Análisis estacional 
Análisis nictímero

ASPECTOS REPRODUCTIVOS

Análisis gonádico

LITERATURA CITADA 


\section{INDICE DE FIGURAS}

Figura 1. Ubicación geográfica del área de estudio y sitios de muestreo.

Figura 2. Extracción de los otolitos

Figura 3. Otolito sagita de M. curema montado en resina epóxica, sin pulir.

Figura 4. Pulido de otolitos sin teñir.

Figura 5.Otolito sagita de M. curema montado en resina epóxica, sin pulir, y teñido.

Figura 6. Montaje de los otolitos en una cápsula.

Figura 7. Corte y obtención de las láminas de los otolitos de M. curema.

Figura 8. Vista de la cara externa del otolito sagita de Mugil curema.

Figura 9. Medidas registradas del otolito.

Figura 10. Promedios para cada uno de los meses de la abundancia en número de M. curema en el hábitat con vegetación sumergida (CVS) y en el hábitat sin vegetación sumergida (SVS).

Figura 11. Promedios para cada una de las horas de la abundancia en número de $M$. curema en ambos tipos de hábitat con vegetación sumergida (CVS) y en el hábitat sin vegetación sumergida (SVS).

Figura 12. Preferencia de la especie por cada una de las condiciones ambientales temperatura, salinidad y oxígeno disuelto para cada hábitat con vegetación y $\sin$ vegetación sumergida.

Figura 13. Variación estacional de los promedios mensuales de las tallas de los organismos capturados de la especie $M$. curema para los dos tipos de hábitat. 
Figura 14. Variación estacional de los promedios por hora de talla de los organismos capturados de la especie M. curema para los dos tipos de hábitat.

Figura 16. Diagrama de la longitud patrón (LP) de los individuos a los que se les extrajeron los otolitos.

Figura 17. Otolito sagita y las características morfológicas relevantes.

Figura 18. Histograma de tallas longitud patrón (LP) de todos los organismos capturados en la laguna de Pueblo Viejo.

Figura 19. EDK donde se muestra la distribución total de tallas y sus grupos modales.

Figura 20. Distribución de frecuencia de tallas (cada $5 \mathrm{~mm}$ ) por mes (ordenados cronológicamente), de todos los individuos de M. curema.

Figura 21. EDKs donde se muestra la distribución mensual de tallas (LP) para $M$. curema incluyendo ambos tipos de hábitats (excepto septiembre). El ancho de banda fue indicado para cada mes por la prueba de Silverman y la regla sobresuavizada de Scott (enero y julio).

Figura 22. Curva de crecimiento estimada de acuerdo al método que aplica el programa de ELEFAN I, Se muestra la línea de crecimiento ajustada que unen las frecuencias modales más importantes para la cohorte de enero, la cual indica el ritmo de crecimiento de la especie en el área de estudio.

Figura 23. Variación mensual del índice gonadosomático (IGS) con respecto a la LP de las hembras de la especie M. curema.

Figura 24. Gónadas de hembras de M. curema 


\section{INTRODUCCIÓN}

El ciclo vital o historia de vida implica directamente aspectos sobre la reproducción y supervivencia de los organismos, por lo que el análisis de la variación en los rasgos de dichos ciclos resulta una herramienta útil, que permite conocer más profundamente como responden evolutivamente las especies a las condiciones $y / 0$ a las perturbaciones ambientales. De hecho, cada organismo sólo puede ser representado adecuadamente mediante su ciclo vital completo (Begon et al., 1999). Las principales características de historia de vida son: tamaño al nacer; patrón de crecimiento; edad en la madurez; talla de madurez; número, tamaño y proporción sexual en la descendencia; edad y tamaño relacionados con el esfuerzo reproductivo y supervivencia; y esperanza de vida (Stearns, 1992).

En relación con los estudios realizados sobre historia de vida en peces y que abordan aspectos como patrón de crecimiento, época reproductiva, talla de madurez, fecundidad y proporción sexual, destacan los trabajos realizados en peces de agua dulce (Blanck \& Lamouroux, 2007) y arrecifes templados (Ziegler et al., 2007), así como los desarrollados para especies de las familias Poeciliidae (FernándezDelgado, 2006), Syngnathidae (Miranda-Marure et al., 2004; Curtis \& Vincent, 2006) y Sciaenidae (White \& Chittenden, 1977; Beckman et al., 1990; Brown-Peterson \& Warren, 2001; Waggy et al., 2006).

Las variables ambientales juegan un papel importante en la distribución de los peces y en los estuarios es aún más marcada dicha importancia, ya que la variación 
constante de los factores ambientales que los caracteriza, afecta a las especies que habitan estos ambientes (Wootton, 1992). En este sentido, estas especies presentan adaptaciones fisiológicas, morfológicas y conductuales (Jumars, 1993), que les permiten resistir los cambios de las diferentes condiciones ambientales, permitiendo así que estas áreas sean ocupadas por una gran diversidad biótica.

Así la distribución de peces estuarinos de acuerdo con algunos autores, puede estar influenciada por el comportamiento de variables ambientales tales como la salinidad, temperatura, oxígeno disuelto y régimen de precipitación (Wootton, 1992; Moyle \& Cech, 2004). Otro factor ambiental importante son las mareas, que ocasionan de alguna manera la sustitución de unas especies por otras (Torres-Orozco, 1994). La estacionalidad de las poblaciones de peces de estuario parece ser creado principalmente por sus respuestas a la temperatura y la salinidad, pero los niveles de oxígeno y la marisma de la vegetación podrían jugar un rol importante. La temperatura es probablemente el factor más importante que afecta la distribución de los peces, tanto espacial como temporalmente, aunque los efectos de la temperatura están estrechamente vinculados a los efectos de otras variables (Moyle \& Cech, 2004). En este sentido la temperatura puede actuar en cualquier etapa del ciclo vital y limitar la distribución de una especie a través de sus efectos en: supervivencia, reproducción y desarrollo de los organismos jóvenes (Krebs, 1985). Moore (1974) reconoció que Mugil curema está aparentemente mejor adaptada a climas tropicales, un hecho que sugiere la importancia de la temperatura del agua para la especie. 
De acuerdo con lo anterior, en un estuario podemos encontrar especies de origen dulceacuícola, marino, eurihalinas y marinas estenohalinas (Blaber, 2002). Particularmente para el Golfo de México, también es posible encontrar especies tropicales, subtropicales y templado-cálidas (Ortiz-Burgos, 2005).

La variabilidad ambiental en los estuarios permite que exista una gran concentración de nutrientes y materia orgánica transportados principalmente por los ríos (Stuardo \& Valdovinos, 1989), lo que hace que los estuarios jueguen un valioso papel en los ciclos biológicos de numerosos organismos marinos, por lo que éstos son usados por muchas especies marinas costeras como áreas de crianza, representando también corredores para aquellas especies que pasan regularmente entre ambientes de agua dulce y marinos como parte de su ciclo de vida normal (Wootton, 1992).

Otro factor importante que afecta la conducta y distribución de los peces y que ha sido poco estudiada, es la periodicidad diaria (variabilidad nictímera) relacionada con la salida y puesta del sol (Helfman, 1993), la cual afecta principalmente actividades fundamentales como la alimentación y reproducción. Así, los procesos de sistemas biológicos marinos y estuarinos varían en tiempo y espacio (Underwood, 1981), por lo que es importante tomar en cuenta cada dimensión (Lipcius \& Subrahmanyam, 1986), así como sus interacciones.

La especie Mugil curema (Valenciennes, 1836) desempeña un importante papel ecológico en los estuarios, por la conversión de energía potencial del detritus en 
energía aprovechable para otros niveles, además al igual que otros mugílidos constituye un importante recurso pesquero (CONAPESCA, 2003). Por su comportamiento biológico, se considera que $M$. curema ocupa un nicho biológico clave entre aguas dulces y aguas saladas. Los caracteres eurihalinos y euritérmicos de los mugílidos facilitan su desplazamiento entre cuerpos de aguas marinas, estuarinas y continentales, lo que permite su utilización en operaciones de acuacultura extensiva y semi-intensiva (Franco \& Bashirullah, 1992). El volumen de producción pesquera en peso vivo de $M$. curema (lebrancha), presenta un total nacional de 4548 ton., de las cuales 4397 (96.7\%) provienen del litoral en el Golfo de México y el Caribe, principalmente Veracruz con 3,934 (86.5\%) y Tamaulipas con $278(6.1 \%)$. Mientras que el volumen de producción pesquera para 2003, en peso vivo de esta especie, proveniente de entidades con litoral en el Pacifico de 151 ton. (3.3\%), principalmente Chiapas con una producción de 132 (2.9\%) y Colima con 13 (0.3\%) (Anuario estadístico 2003).

M. curema es una especie de amplia distribución, reportándose en el Atlántico Occidental desde Nueva Escocia (raramente al norte de Cape Cod), Las Bermudas y el norte del Golfo de México, hasta el sur de Brasil. En el Atlántico oriental se distribuye desde Senegal a Namibia, mientras que en el Pacífico Oriental su distribución va desde el Golfo de California hasta Chile (Ibáñez-Aguirre et al., 2006). 
En la laguna de Pueblo Viejo, $M$. curema se ubica dentro de las diez especies más abundantes en número y peso. Así, para el ambiente con vegetación sumergida, de 67 especies representa el $5.9 \%$ en número y el $14.5 \%$ en peso, y para el ambiente sin vegetación sumergida, de 54 especies representa el $0.91 \%$ en número y el $4.30 \%$ en peso (Castillo-Rivera \& Zárate-Hernández, 2001, Zárate-Hernández, 2003; Castillo-Rivera et al., 2003; Ortiz-Burgos, 2005)

\section{ANTECEDENTES Y JUSTIFICACIÓN}

Entre los trabajos realizados acerca de $M$. curema destacan aquellos realizados en Venezuela, los cuales revisan aspectos sobre dinámica de reclutamiento de juveniles (Ferrer-Montaño, 1994), crecimiento y madurez sexual (Toledo et al., 1997), reproducción y reclutamiento (Marin et al., 2003), edad, crecimiento y fecundidad (Marin \& Dodson, 2000). En el Caribe se revisan aspectos sobre la biología de la reproducción (Solomon \& Rammarine, 2007) y particularmente en Cuba se han realizado estimaciones de fecundidad (Alvarez-Lajonchere, 1982). En el Atlántico sur de los Estados Unidos, se estudia el crecimiento (Anderson, 1957), mientras que en Texas se analiza la ecología general y la abundancia relativa (Moore, 1974) y en Virginia se reporta un estudio de crecimiento y distribución local (Richards \& Castagna, 1976).

En México y específicamente para el Pacífico mexicano se cuenta con trabajos relacionados con edad y crecimiento (López-Olmos, 2000; Espino-Barr et al., 2005), 
abundancia (Muhlia-Almazán et al., 2003). Particularmente en Baja California Sur se analiza el cambio estacional de la abundancia relativa, la estructura de tallas y la relación longitud peso de los juveniles (Quiñonez-Velázquez \& Mendoza-Guevara, 2009). Para el Golfo de México se han realizado trabajos sobre: morfometría y crecimiento (Pérez-García \& Ibáñez-Aguirre, 1992; Ibáñez-Aguirre \& Leonart, 1996; Ibáñez-Aguirre, et al., 1999), alimentación (Sánchez-Rueda et al., 1997; SánchezRueda, 2002) y reproducción (Ibáñez-Aguirre, 2004). Tomando en cuenta ambos Pacifico y Golfo de México, se cuenta con un estudio de morfometría (Ibáñez-Aguirre et al., 2006).

Específicamente para la laguna de Pueblo Viejo, Veracruz, sólo se cuenta con un estudio sobre algunos aspectos de la biología de M. curema (Rivera-Bernal, 1981), aunque se sabe que es una de las especies con mayor importancia en número y biomasa dentro de este sistema, lo cual ha quedado mostrado tanto en ciclos de muestreos diurnos (Castillo-Rivera, 1995; Castillo-Rivera \& Zárate-Hernández, 2001; Castillo-Rivera et al., 2003a; 2003b), como en ciclos donde se considera la variabilidad nictímera (Zárate-Hernández, 2003, Ortiz-Burgos, 2005; Castillo-Rivera et al., 2005).

A pesar de la importancia económica y ecológica de la especie los estudios sobre su historia de vida aún resultan insuficientes y todavía más en el área de estudio, por lo que cualquier aporte al conocimiento de su ciclo biológico, contribuirá al mejor aprovechamiento y uso racional de la misma. 


\section{OBJETIVOS}

\subsection{OBJETIVO GENERAL}

- Describir y analizar las principales características de historia de vida de Mugil curema (Valenciennes, 1836), así como el comportamiento espacial y temporal de su abundancia, en la laguna de Pueblo Viejo, Veracruz.

\subsection{OBJETIVOS ESPECÍFIC}

- Analizar las variaciones espaciales, estacionales y nictímeras en la abundancia relativa de la especie.

- Analizar la influencia de las condiciones ambientales sobre la abundancia de la especie.

- Analizar las variaciones espaciales, estacionales y nictímeras en la estructura de tallas de la especie, así como los patrones de crecimiento, talla de madurez.

- Analizar las variaciones estacionales de los aspectos relevantes de la biología reproductiva de la especie. 


\section{MATERIAL Y MÉTODO}

\section{1 ÁREA DE ESTUDIO}

La Laguna de Pueblo Viejo se localiza al norte del estado de Veracruz entre los paralelos $22^{\circ} 05^{\prime}$ y $22^{\circ} 15^{\prime}$ latitud norte, y meridianos $97^{\circ} 50^{\prime}$ y $98^{\circ} 00^{\prime}$ longitud oeste, entre las provincias zoogeográficas Carolina y Caribeña. El sistema es relativamente pequeño con una superficie aproximada de $88.7 \mathrm{~km}^{2}$, con una longitud máxima en sentido norte-sur de $13.5 \mathrm{~km}$ y una anchura mayor en sentido este-oeste de $11 \mathrm{~km}$ (Castillo-Rivera, 1995). El área de estudio presenta un clima cálido sub-húmedo, con una época de lluvias de junio a octubre (con precipitaciones mayores a $120 \mathrm{~mm}$ ) y una de secas, de noviembre a mayo (con precipitaciones menores a los $50 \mathrm{~mm}$ ) (Figura 1)

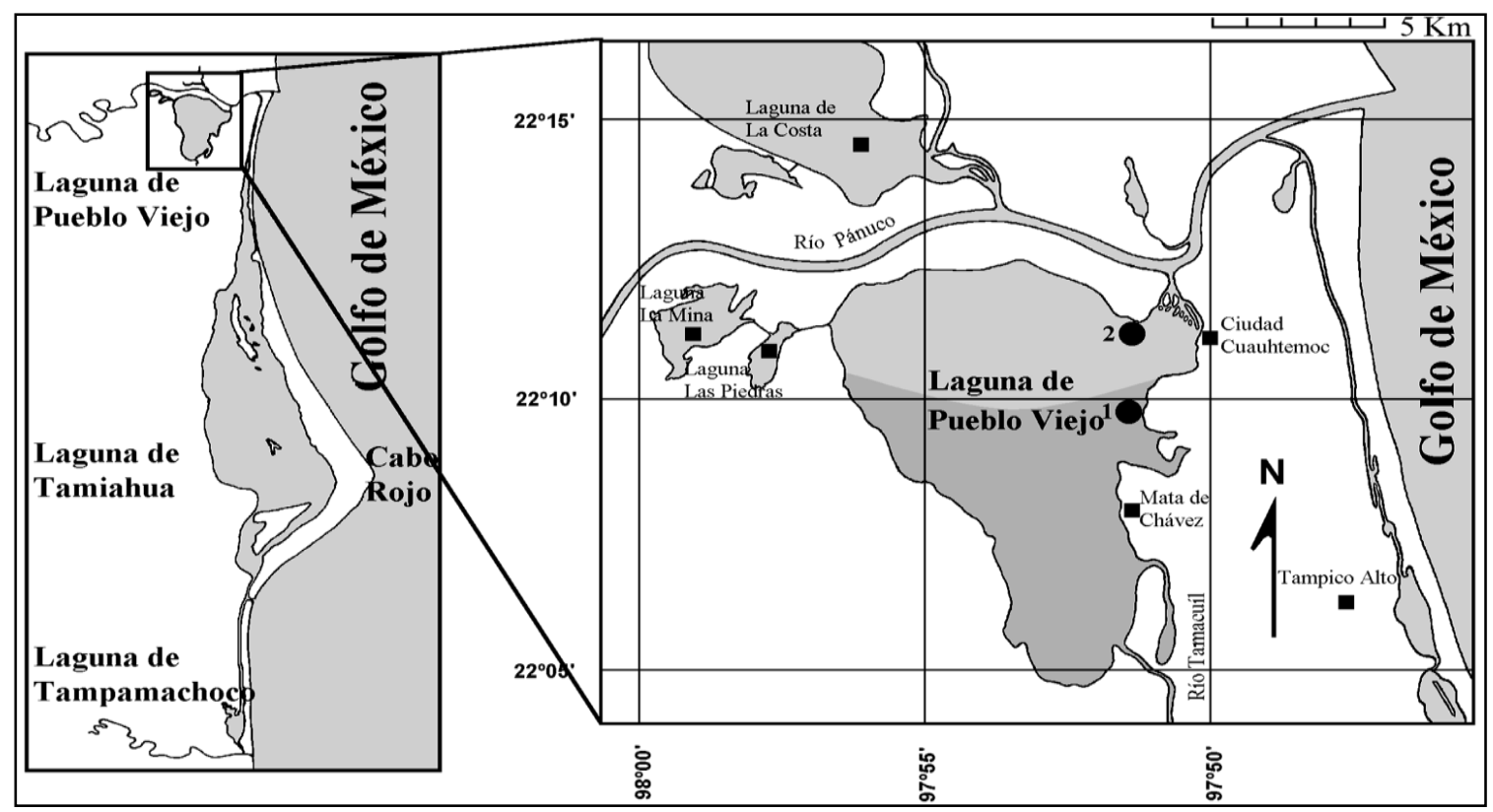

Figura 1. Ubicación geográfica del área de estudio y sitios de muestreo, hábitat con vegetación sumergida (1) y hábitat sin vegetación (2). 
La laguna está conectada en su porción noreste con el río Panuco, aproximadamente $10 \mathrm{~km}$ de la desembocadura de éste en el Golfo de México, por lo que se le puede considerar un estuario de comunicación restringida y en la porción sur recibe una importante descarga del río Tamacuil. Esta situación genera un gradiente de salinidad el cual decrece de norte a sur, generándose dos subsistemas estuarinos (Castillo-Rivera et al., 1996), uno hacia el sur, que representa un hábitat de mayor influencia dulceacuícola con densos lechos de Ruppia marítima, esta vegetación empieza a desarrollar aproximadamente a $5 \mathrm{~m}$ de orilla alcanzando una anchura de $35 \mathrm{~m}$ aproximadamente y otro al norte, que se tipifica como un el hábitat de influencia marina, en el cual prácticamente no existe una vegetación sumergida. El pasto $R$. marítima es una especie eurihalina, que se encuentra comúnmente en zonas que presentan una fuerte oscilación en la salinidad (Castillo-Rivera, 1995).

La vegetación costera emergente está dominada por un manglar cuya amplitud varia de los 40 a $600 \mathrm{~m}$, el cual se constituye por cuatro especies, las cuales de acuerdo a su abundancia son: mangle negro (Avicennia germinans), mangle blanco (Laguncularia racemosa) y mangle rojo (Rizophora mangle) y botoncillo (Conocarpus erectus) (Castillo-Rivera et al., 2005).

La presencia de manglar juega un papel importante dentro de los estuarios debido al aporte de materia orgánica alóctona con la que contribuye, lo que favorece el fortalecimiento de la ruta trófica detritívora de estos sistemas (Castillo-Rivera et al., 2003a). 


\subsection{COLECTA DEL MATERIAL BIOLÓGICO}

El material biológico analizado, forma parte de la Colección del Laboratorio de Peces del Departamento de Biología (DCBS) de la Universidad Autónoma Metropolitana, Unidad Iztapalapa.

\subsubsection{Muestreo y preservación del material}

Las recolectas de los individuos se realizaron utilizando un chichorro playero de $30 \mathrm{~m}$ de largo con una profundidad de $1 \mathrm{~m} \mathrm{y} 1 \mathrm{~cm}$ de luz de malla, comprendiendo aproximadamente un área de muestreo de $1500 \mathrm{~km}^{2}$. Inmediatamente después de capturar los individuos, estos fueron fijados en formaldehído al 10\% y en laboratorio fueron lavados con agua y el material fue colocado en frascos de vidrio y conservados en alcohol etílico al 70\%.

El material analizado corresponde a muestreos bimestrales, durante un año (19891990), con recolectas cada dos horas en 12 ciclos nictímeros, en dos diferentes tipos de hábitat, uno con vegetación sumergida y otro sin este tipo de vegetación.

\subsubsection{Variables ambientales}

Las variables ambientales consideradas fueron la temperatura, la cual se midió con un termómetro de mercurio; la salinidad que fue determinada con un refractómetro de campo y oxígeno disuelto, el cual se determinó mediante el método de Winkler. 


\subsection{BIOMETRÍA}

A cada individuo se le determinó: longitud total $(\mathrm{mm})$, longitud patrón $(\mathrm{mm})$, peso total (g), peso de las gónadas derecha e izquierda (g), medidas de los otolito (largo y ancho) izquierdo y derecho $(\mu \mathrm{m})$. Las medidas de longitud se determinaron con un calibrador Fowler de $0.02 \mathrm{~mm}$ de precisión y las medidas de peso con una balanza Ohaus GT 480 de $1 \mathrm{mg}$ de precisión y cuando fue necesario una balanza analítica OHAUS de $0.1 \mathrm{mg}$ de precisión, las medidas de los otolito se realizaron utilizando un microscopio compuesto de la marca Olympus modelo BX5.

\subsection{DISTRIBUCIÓN ESPACIO-TEMPORAL}

Para analizar los cambios espaciales de la distribución de la especie en la laguna de Pueblo Viejo, se consideraron los dos tipos de hábitat, el de influencia marina, sin vegetación sumergida (SVS), y el de influencia dulceacuícola con densos lechos de Ruppia marítima (CVS). Para evaluar los cambios estacionales se analizaron los seis períodos mensuales de recolecta realizados en cada localidad, así como las épocas de secas (de noviembre a mayo) y de lluvias (de junio a octubre). Para evaluar los cambios nictímeros se tomaron en cuenta las horas en que se capturaron los peces, así como el día (06:00 a 18:00 h) y la noche (20:00 a 04:00 h).

\subsection{DISTRIBUCIÓN YABUNDANCIA}

Para el análisis de los diferentes aspectos de distribución y abundancia, se utilizaron análisis de varianza de tres factores, considerando simultáneamente el factor 
espacial con dos niveles (con y sin vegetación sumergida), el estacional con cada uno de los meses considerados (6 niveles) y níctimero (día/noche), así como la interacción entre estos factores. Similarmente para la estructura de tallas, también se aplicó un análisis de varianza de tres factores para evaluar cambios significativos entre los diferentes niveles de los factores espacial, estacional y nictímero, así como para evaluar la interacción que existe entre éstos (Zar, 1999)

\subsubsection{Influencia de las condiciones ambientales sobre la abundancia}

La influencia de las condiciones ambientales sobre la abundancia de la especie fue estimado por medio de correlaciones simples (correlación de Spearman o Person), previa evaluación de los supuestos (Zar, 1999).

\subsection{GRUPOS DE EDAD (COHORTES) Y CRECIMIENTO}

La determinación de la edad de los individuos de una población constituye un elemento fundamental para estimar parámetros demográficos y procesos ecológicos (Ibáñez-Aguirre \& Gallardo-Cabello, 1996, Christopher-Chambers \& Miller, 1995, Panfili et al., 2001). Así, el análisis de la edad es uno de los procesos más importantes para la descripción de la estructura de una población y su comportamiento en el estudio de la dinámica de las poblaciones (Ibáñez-Aguirre et al., 2005). En este sentido, para la determinación de probables grupos de edad se pueden utilizar métodos directos e indirectos.

Los métodos directos están relacionados con la observación directa de las discontinuidades del crecimiento en estructuras óseas, como producto de cambios en 
el metabolismo de los individuos y su correlación con el tiempo en que ocurrieron (Gómez, 1994, Lai et al., 1996), las cuales se forman regularmente en periodos determinados. La interpretación de estas zonas depende de su continuidad y calidad del tejido (Weatherley, 1987). Cuando se forman anualmente, se les suele llamar marcas anuales o annulli. Sin embargo, la periodicidad de formación de las marcas puede o no definirse anualmente y éstas deben ser determinadas para cada una de las clases de la población (Morales-Nin, 1991; Scott-Baker \& Wilson, 2001). Las estructuras óseas comúnmente utilizadas para la determinación de la edad son: escamas, otolitos y vértebras (Cabrera-Neri, 2002).

La formación de anillos de crecimiento en los tejidos calcificados de los peces óseos es causada, al menos en parte, por los cambios estacionales del medio (Morales-Nin, 1991). Blake y Blake en 1978 (en: Weatherley, 1987) concluyen que en los trópicos la formación de estas marcas, varia en el tiempo e intensidad año con año. Según Morales-Nin (1991), en las zonas tropicales dichos cambios periódicos (ciclos de temperatura, disponibilidad de alimento, etc.), son más limitados e irregulares durante la historia de vida de un pez.

Para observar los probables grupos de edad y el crecimiento se utilizaron métodos directos e indirectos. 


\subsubsection{Determinación de la edad (Método directo)}

Para la determinación de la edad vía método directo, se encontró que los otolitos proporcionan un registro del crecimiento más adecuado que las escamas (RochaOlivares \& Gómez-Muñoz, 1993). Por lo anterior, en el presente estudio se consideró el otolito sagita.

\subsubsection{Selección de otolitos}

Los otolitos fueron seleccionados con base en el análisis de la distribución de tallas, por medio de un diagrama de tallo y hoja, considerando ambos hábitat, con vegetación sumergida (CVS) y sin vegetación sumergida (SVS). Esta selección dependió del número de modas observadas en dichos diagramas, se seleccionaron 85 individuos organismos que fueran representativos de dichas modas. De cada organismo se registró la longitud total (LT) (mm) y la longitud patrón (LP) (mm).

\subsubsection{Extracción de otolitos}

Para la extracción de las estructuras se siguió y modificó la técnica descrita por Brothers (1987) y Morales-Nin (1991), realizándose dos tipos de cortes dependiendo del tamaño del organismo; en los individuos más grandes el corte se hizo en la parte posterior del cráneo y en los pequeños un corte en el paladar, lo cual permitió acceder al interior de las cámaras óticas (Figura 2), extrayéndose los otolitos con pinzas de disección. Durante la disección, se anotó su posición (derecho o izquierdo), ya que sus características morfológicas pueden estar relacionados con la posición de los mismos (Brothers, 1987). Una vez extraídos los otolitos, se limpiaron 
de los tejidos adjuntos, con la ayuda de un pincel o de unas pinzas, bajo el microscopio estereoscópico. Las muestras fueron inmersas en una solución de peróxido de hidrógeno durante varios minutos para ayudar a disolver los tejidos resistentes, pero no se observaron cambios favorables. Por el contrario, los otolitos descalificados ya de por sí, por el prolongado período de conservación de los organismos, se descalcificaron aún más con esta solución. Una vez limpios se secaron y se almacenaron en seco dentro de microtubos de centrifuga con la debida referencia.
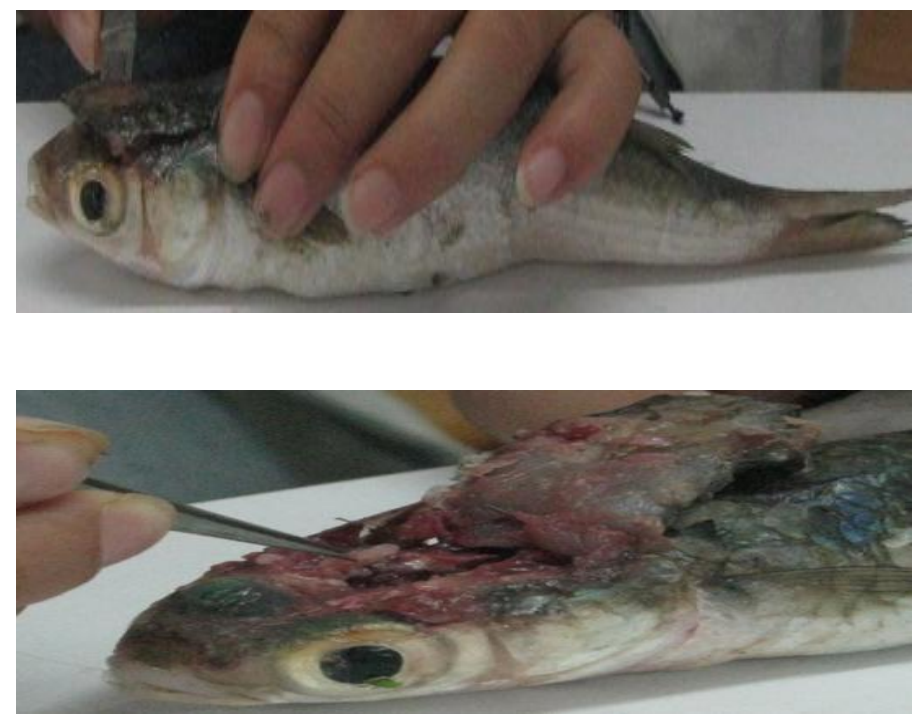

Figura 2. Extracción de los otolitos.

\subsubsection{Montado y pulido de otolitos}

Para la identificación de los anillos de crecimiento, se modificó la técnica descrita por Ibañez-Aguirre y Gallardo-Cabello (1996). Los otolitos fueron colocados en cajas petri y observados por medio de un microscopio estereoscópico marca Carl Zeiss modelo Stemi DV4, empleando iluminación transmitida. Con este tipo de iluminación los anillos de crecimiento no se observaban claramente, por lo que se probó la 
técnica de quemado y horneado de acuerdo con Cabrera-Neri (2002). Los otolitos se colocaron en cajas petri y se metieron al horno en combinación de tiempo y temperatura, sin embargo se observó que con el horneado, los otolitos comenzaron a deshacerse, por lo que no se continuó con esta técnica.

Se probaron además las técnicas de pulido sin teñir, pulido y teñido, corte transversal de otolito y la inmersión de los otolitos en xilol y glicerina como líquido aclarante, estas técnicas se describen a continuación.

Para la técnica de pulido sin teñir, los otolitos se montaron de acuerdo a Morales-Nin et al. (1999), colocándose una pequeña gota de resina epóxica S-2400 en un portaobjetos. Una vez que la gota endureció y secó por completo, se colocó el otolito (de forma que quedará expuesta la cara interna) sobre ésta y se agregó más resina para fijar el otolito al portaobjetos (Figura 3). De esta forma, los otolitos se pulieron, siguiendo el método propuesto por Morales-Nin et al. (1999). El pulido se realizó con una lija de agua del número B-99, frotando el portaobjetos, con la muestra, contra la lija en movimientos en forma de 8 (Figura 4). Constantemente se observó la preparación al estereoscopio (marca Olympus SZ51, modelo SZ2-ILST) para no sobre pulir el otolito. El pulido final se hizo con una pasta para pulir discos compactos marca Pulidisc, sosteniendo el portaobjetos con la mano sobre la pasta. Bajo estas condiciones no se observaron claramente los anillos de crecimiento. 


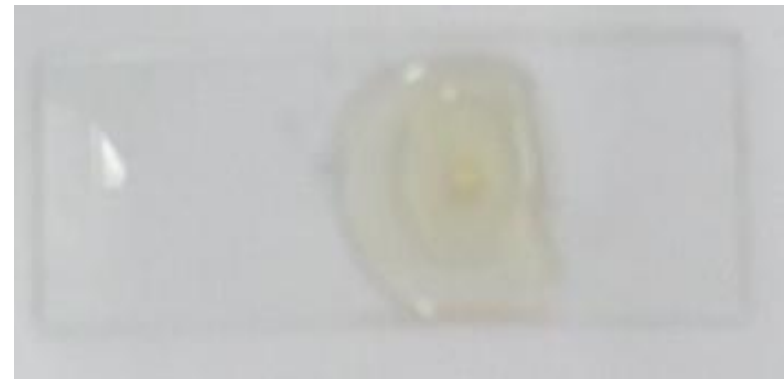

Figura 3. Otolito sagita de $M$. curema montado en resina epóxica, sin pulir.

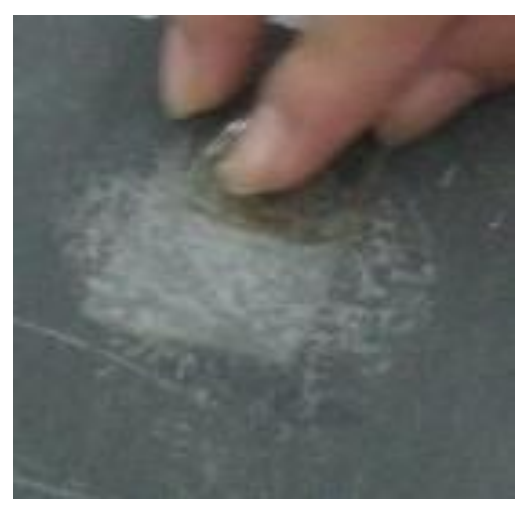

Figura 4. Pulido de otolitos sin teñir.

En la técnica de pulido y teñido, se siguió el procedimiento descrito por Morales-Nin et al. (1999) y Alagador y Murta (2002). Los otolitos fueron inmersos en una solución de rojo neutro ( $1 \mathrm{~g}$ de cloruro de sodio y $0.5 \mathrm{ml}$ de ácido acético glacial para $100 \mathrm{ml}$ de rojo neutro al $0.33 \%$ ) por 10 minutos. Posteriormente, el otolito se montó en un portaobjetos con resina epóxica. El montaje fue realizado de la misma manera que en la técnica de pulido sin teñir. Con esta técnica, tampoco se evidenciaron los anillos de crecimiento, además el sulco acústico (presente en la cara interna) no permitió apreciar la continuidad de potenciales anillos de crecimiento (Figura 5). 

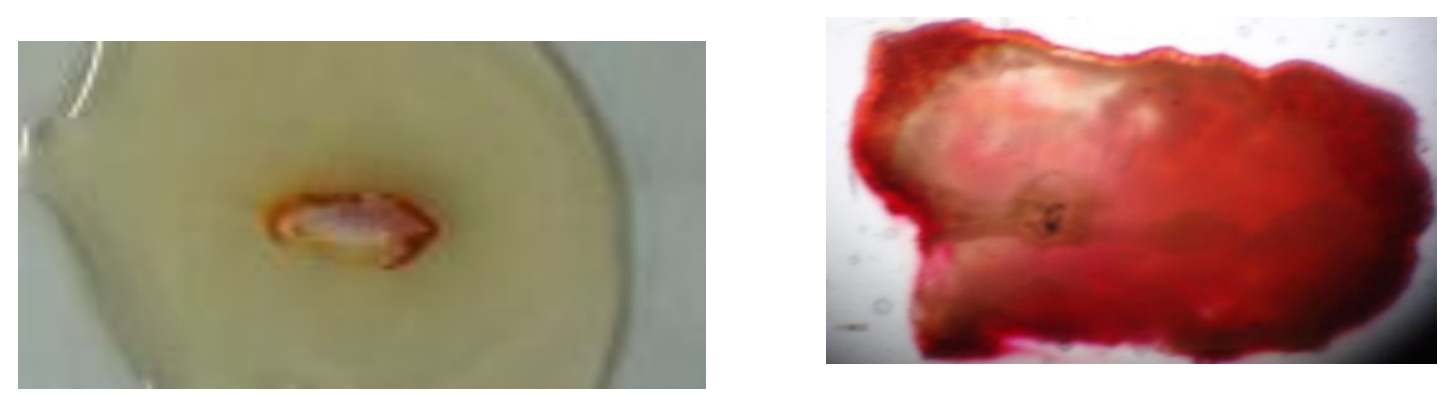

Figura 5. Otolito sagita de $M$. curema montado en resina epóxica, sin pulir, y teñido.

Se probó también, el corte transversal del otolito. Para esto, los otolitos se incluyeron en resina epóxica dentro de moldes de capsulas de plástico. Se vertió una pequeña cantidad de resina en el molde y se esperó hasta que la resina quedará sólida. Los otolitos se situaron sobre la resina, orientados horizontalmente para facilitar el corte. Posteriormente los moldes se llenaron con la resina procurando no formar burbujas. Los moldes se almacenaron en un lugar protegido del polvo y se dejó que la resina solidificara durante 24 horas. Una vez que la resina endureció, se eliminó el molde, ya sea desprendiéndolos del bloque o sumergiéndolos en agua para que se disolviera la cápsula (Figura 6).
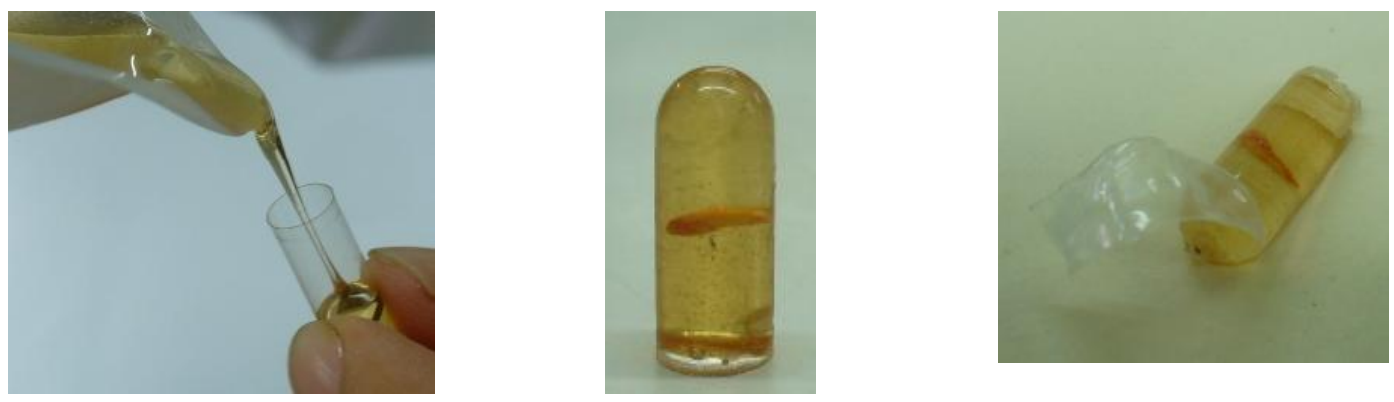

Figura 6. Montaje de los otolitos en la cápsula para el corte posterior. 
El corte transversal de los otolitos se realizó situando el bloque sobre una superficie semirrígida utilizando una segueta del número $2 / 0$, procurando que el foco del otolito quedara incluido en el corte. Este corte se realizó de forma cuidadosa para evitar la rotura de la estructura y la obtención de una lamina fina que permitiera apreciar las marcas de crecimiento (Morales-Nin et al., 1991) (Figura 7).
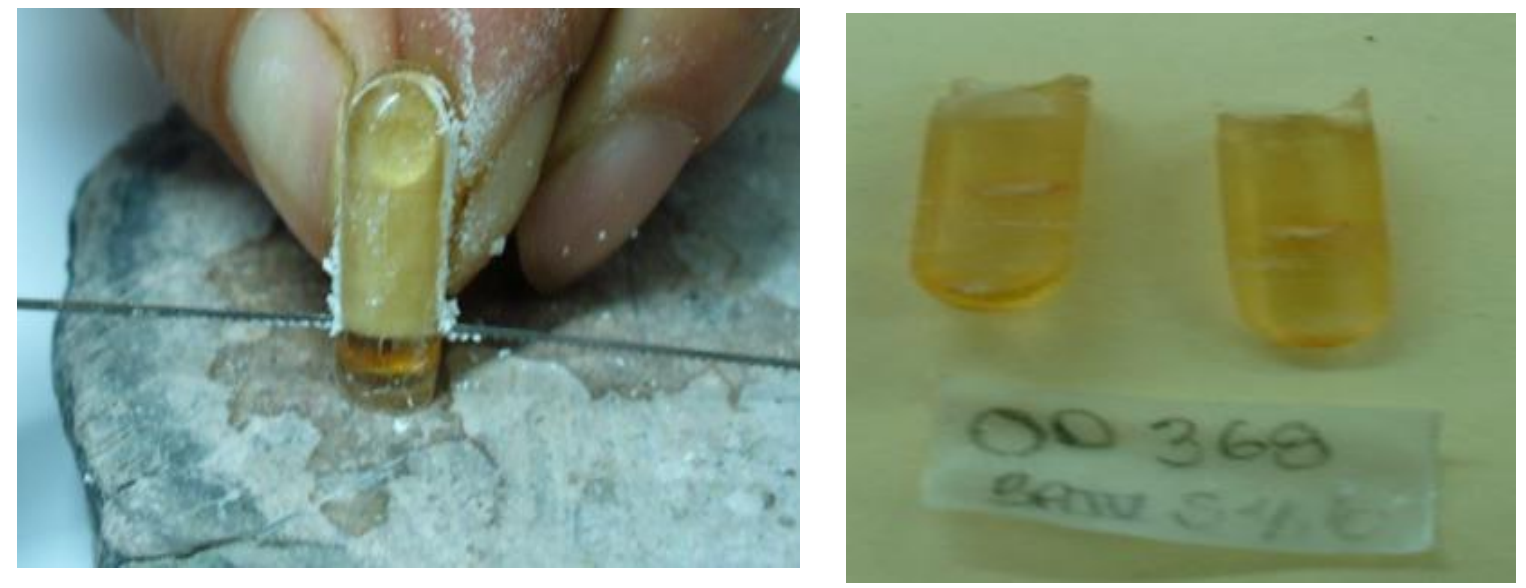

Figura 7. Corte y obtención de las láminas de los otolitos de M. curema.

Una vez obtenido el corte del otolito, éste se pulió con ayuda de una lija de agua, para eliminar las irregularidades de la superficie. Este proceso se realizó cuidadosamente, observando continuamente la muestra con un microscopio estereoscópico a fin de evitar sobrepulir o erosionar los bordes del otolito. Posteriormente, el corte pulido se adhirió a un portaobjetos con resina epóxica. Con esta técnica se logró apreciar microlíneas, pero no las bandas de crecimiento.

Por último, se probó la técnica de inmersión de los otolitos en xilol como liquido aclarante, siguiendo la técnica descrita por Ibañez-Aguirre y Gallardo-Cabello (1996). 
Los otolitos se limpiaron y lavaron en una solución de agua con detergente, dejándose 15 minutos, con el fin de eliminar tejido orgánico, posteriormente se sumergieron en una solución de xilol absoluto aproximadamente durante 30 minutos. Después de este tiempo se sacaron de la solución de xilol y se observaron al microscopio estereoscópico. Con esta técnica tampoco se observaron claramente los anillos de crecimiento (Figura 8). De la misma manera se realizó la inmersión de los otolitos con glicerina, pero tampoco se obtuvieron resultados inequívocos (adecuados).
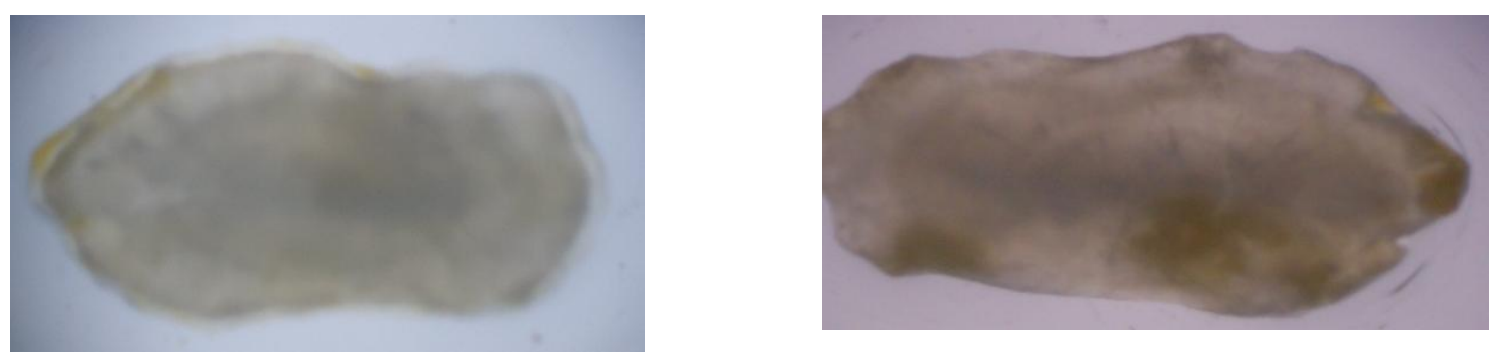

Figura 8. Vista de la cara externa del otolito sagita de Mugil curema.

La descripción de la morfología de los otolitos sagita de $M$. curema se realizó siguiendo los criterios de Mascareñas-Osorio et al. (2003), tomando en cuenta la forma y las ornamentaciones de la cara interna, con el fin de observar características distintivas de esta especie y ubicar las regiones del otolito (Martínez-Pérez et al., 2007).

Con el fin de explicar las relaciones alométricas del otolito, se realizó un análisis morfométrico de las dimensiones (largo y ancho) de estas estructuras (Fig. 9). La 
estimación de estas relaciones permite describir las características bidimensionales de la población (Morales-Nin, 1991, Rocha-Olivares \& Gómez-Muñoz, 1993).

En este sentido, a los otolitos extraídos se les midió el largo y el ancho máximo (Lombarte \& Lleonart, 1993) (Figura 9), utilizando un microscopio compuesto de la marca Olympus modelo BX5. Las mediciones se efectuaron usando la escala micrométrica que contiene la reglilla del ocular, la cual está graduada de acuerdo con el objetivo. En el presente caso se utilizó el objetivo 2x y cada división de la reglilla del ocular equivalió a $50 \mu \mathrm{m}$.

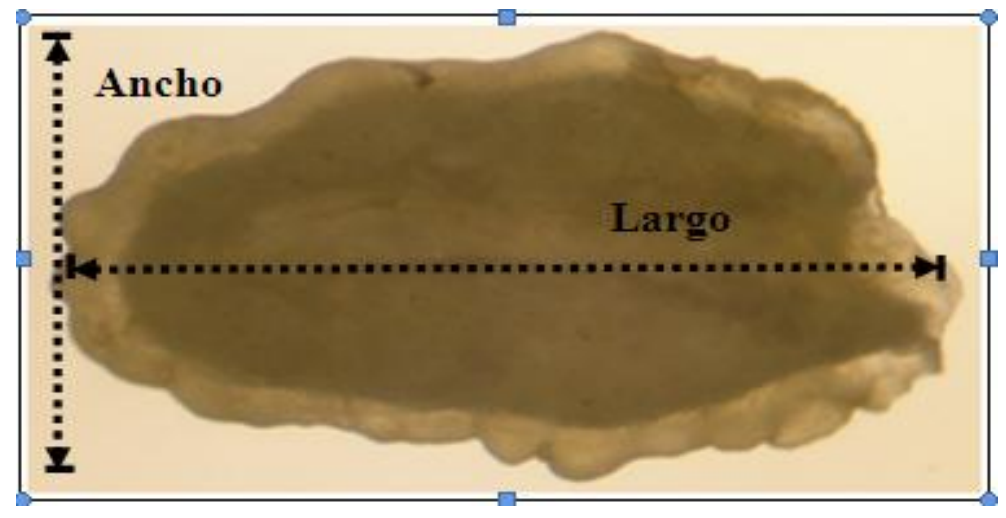

Figura 9. Medidas registradas del otolito, de acuerdo con Lombarte y Lleonart (1993).

Para evaluar posibles diferencias entre los otolitos derecho e izquierdo, se usaron las medidas largo y ancho a través de la prueba de Wilcoxon, ya que ésta se emplea en procedimientos en donde las variables están correlacionadas (análisis pareado). Se usó ésta y no la distribución de t-student, porque la estructura de los datos no presentó normalidad (Zar, 1996). 


\subsubsection{Relación longitud patrón de los organismos-medidas del otolito}

En las especies de peces, la relación entre longitud patrón del organismo y diferentes medidas del otolito, puede ser descrita por una regresión potencial (Lombarte \& Lleonart, 1993). La ecuación de regresión potencial $\left(y=a x^{b}\right)$ fue considerada el modelo ordinario alométrico y se determinó la pendiente de alometría, realizando regresiones (previa transformación logarítmica) de cada una de las variables, tomando como variable independiente $(\mathrm{x})$ la longitud patrón (LP) y dependiente $(\mathrm{y})$ las medidas del otolito. Las pendientes de las relaciones se compararon con el valor hipotético de isometría utilizando la prueba t-student, con un nivel de confianza del 95\% (Zar, 1996):

$$
t=\frac{b-1}{S b}
$$

Donde: $\mathrm{t}=$ estadístico de prueba

$b=$ pendiente de la relación longitud patrón-promedio del otolito $S_{b}=$ error estándar de la pendiente

Si la pendiente es igual a 1 entonces la relación será isométrica, esto significa que las proporciones del organismo se mantienen constantes a través de su crecimiento (McMahon \& Bonner, 1986). En cambio si la pendiente es diferente de 1 entonces implica que la longitud del otolito no se mantiene constante a través de su crecimiento. 


\subsubsection{Relación longitud patrón-peso del pez}

La alometría indica el tipo de crecimiento relativo proporcional entre dos estructuras. Si la estructura crece más rápido que alguna otra tomada como estándar, se dice que exhibe una alometría positiva, en cambio si el crecimiento es más lento se denomina alometría negativa (Ramos-Jilberto, 1995, lannacone \& Alvariño, 2007).

La talla (LP) y el peso constituyen, una base para la determinación del crecimiento relativo, conociendo las tallas y los pesos de una población se puede conocer la estructura de la misma, ya que las distribuciones de esas medidas son reflejo de las interacciones entre las tasas de reproducción y crecimiento (Lorenzo-Nespereira, 1992).

Así, se calculó, para todos los individuos a los que se les extrajo otolitos, la relación entre la longitud patrón y el peso. También se realizó dicho análisis por separado, es decir, para los individuos que pertenecían al los hábitats con y sin vegetación. La relación esta descrita por la función potencial que describe el crecimiento relativo (Ricker, 1973), cuya ecuación es $y=a x^{b}$, donde " $y$ " es la variable dependiente (peso) y " $x$ " es la variable independiente (longitud patrón). Para estimar los valores de las constantes de la relación (a y b) se utilizó el análisis de regresión lineal simple, sobre las variables transformadas a logaritmo base 10 (Spiegel et al., 2003), para ajustar dicha relación a una línea recta, de esta forma la ecuación queda: $\log$ peso $=\log a+$ b log LP. Para conocer el tipo de alometría se uso la prueba de t-student con un nivel de confianza del 95\% (Zar, 1996), de acuerdo con la siguiente ecuación: 


$$
t=\frac{b-3}{S b}
$$

Donde: $\mathrm{t}=$ estadístico de prueba

$b=$ pendiente de la relación longitud patrón-peso

$\mathrm{S}_{\mathrm{b}}=$ error estándar de la pendiente

Cuando la pendiente de la relación longitud patrón-peso es igual a 3 el crecimiento relativo del organismo se considera isométrico y entonces las proporciones del organismo se mantienen constantes a través de su crecimiento; cuando la pendiente es mayor a 3 el crecimiento relativo se considera alométrico positivo, que indica un crecimiento mayor en peso que en longitud, y cuando la pendiente es menor a 3 el crecimiento relativo es alométrico negativo, que indica un mayor crecimiento en longitud que en peso (Ricker, 1975).

\subsection{Distribución de frecuencias de tallas (Método indirecto)}

Para determinar el crecimiento alcanzado por la especie $M$. curema, también se utilizaron métodos basados en la distribución mensual de la frecuencia de tallas (Poligono de frecuencia y EDKs), como una alternativa a los métodos de evaluación directos, que en el presente caso mostraron poca evidencia de anillos de crecimiento en los otolitos.

Para determinar la cohorte de cada grupo de edad para cada talla, se integró una base de datos con las longitudes patrón $(\mathrm{mm})$ de 1,149 individuos de $M$. curema. Se 
agruparon los datos mensualmente y se determinó su frecuencia de longitudes a fin de utilizarse el método indirecto para determinar la edad y el crecimiento. Se elaboraron los histogramas correspondientes, distribuyendo los organismos en clases de $5 \mathrm{~mm}$ y las graficas se ordenaron cronológicamente.

Para el análisis de frecuencia de tallas se utilizaron los estimadores de densidad por kernel (EDKs) con función Gaussiana mediante los programas escritos por SalgadoUgarte et al. (1993a, 1995a, 1995b, 2005) con el paquete estadístico Stata 9.1.

Para la determinación de los parámetros de crecimiento se utilizó el método indirecto de progresión modal a partir de las frecuencias de tallas (LP) mensuales representadas por EDKs, utilizando el programa computacional ELEFAN I (Electronic Length Frecuency Análisis) (Brey y Pauly, 1986) integrado en el programa FiSAT (FAO ICLARM Stock Assessment Tools) (Gayalino et al., 1996). El crecimiento se ajustó al descrito por la función de von Bertalanffy (VBGF), el índice de bondad de ajuste denominado $R n$ es usado para evaluar la mejor combinación de $\mathrm{L}_{\infty}$ y K (Gulland \& Rosenberg, 1992).

Asimismo se realizó un análisis exploratorio de la distribución mensual de frecuencia de talla, para determinar las clases modales, necesarias para el cálculo del crecimiento, que se comprobaron mediante los estimadores de EDKs. 


\subsection{ASPECTOS REPRODUCTIVOS}

\subsubsection{Análisis gonádico}

La reproducción es uno de los procesos biológicos más importantes mediante el cual se logra que las especies se perpetúen en el tiempo. Cada grupo de peces tiene un desarrollo gonadal muy particular y una talla de primera madurez que difiere entre especies. En el caso particular de M. curema sin embargo pocos son los estudios que se han realizado sobre aspectos reproductivos.

Para interpretar las variaciones del desarrollo gonadal y detectar los cambios en la actividad reproductiva, se utilizó el índice gonadosomático (IGS). El IGS es un método que se utiliza para poder determinar el estado de madurez de las gónadas en un periodo determinado y es la manera de saber cuál es la época en la que los peces tienen la capacidad de reproducirse, siendo éste un indicador del desarrollo gonadal en especies que muestran estacionalidad en sus ciclos reproductivos (LucanoRamírez et al., 2005; Cruz-Gomez et al., 2010).

El estado de madurez de las hembras fue determinado mediante un examen macroscópico de los ovarios, considerando el color, transparencia y tamaño de los ovocitos. Para el análisis del índice gonadosomático (IGS) se analizaron un total de 144 gónadas de hembras. Este índice se analizó principalmente a nivel estacional, para evaluar aspectos reproductivos de la especie a lo largo del año. 
El índice gonadosomático (De Vlaming et al., 1982) se calculó de acuerdo a la siguiente ecuación:

$$
I G S=\left(\frac{P G}{P T}\right) * 100
$$

Donde:

IGS= Índice gonadosomático

$P G=$ Peso de la gónada

$\mathrm{PT}=$ Peso total del pez

\section{ANÁLISIS ESTADÍSTICO}

Se realizaron diferentes pruebas de inferencia estadística, para determinar si existían o no diferencias significativas. Para el efecto se utilizaron los paquetes estadísticos SPSS y NCSS 2000 .

\section{RESULTADOS}

\subsection{DISTRIBUCIÓN Y ABUNDANCIA}

\section{Análisis espacial}

A nivel espacial la abundancia promedio en el hábitat con vegetación sumergida $(\bar{x}=$ 13.99) fue mayor que en el hábitat sin vegetación $(\bar{x}=2.44)$, siendo estas diferencias significativas (Tabla 1). Asimismo, estas diferencias fueron independientes de la variabilidad estacional $(P=0.101)$ y de la variabilidad nictímera $(P=0.213)$. 
Tabla 1. Resultados de la aplicación del ANOVA de tres factores a la abundancia en número de la especie Mugil curema.

\begin{tabular}{lccccc}
\hline \multicolumn{1}{c}{$\begin{array}{c}\text { Origen } \\
\text { Variabilidad }\end{array}$} & $\begin{array}{c}\text { Suma de } \\
\text { Cuadrados }\end{array}$ & g.l & Cuadrados & Medios & Probabilidad \\
\hline Espacial & 3635.852 & 1 & 3635.852 & 4.561 & 0.035 \\
Estacional & 15661.4 & 5 & 3132.28 & 3.93 & 0.003 \\
Nictímero & 1844.472 & 1 & 1844.472 & 2.314 & 0.131 \\
Espacial/estacional & 7534.63 & 5 & 1506.926 & 1.891 & 0.101 \\
Espacial/nictímero & 1250.433 & 1 & 1250.433 & 1.569 & 0.213 \\
Estacional/nictímero & 6709.213 & 5 & 1341.843 & 1.683 & 0.144 \\
Error & 90867.448 & 114 & 797.083 & & \\
Total & 150066 & 138 & & & \\
\hline
\end{tabular}

\section{Análisis estacional}

Estacionalmente también existieron diferencias significativas entre los promedios mensuales, observándose el mayor número de individuos en enero para ambos hábitats, mes después del cual la abundancia declinó progresivamente (Figura 10). Además, no hubo una interacción significativa entre la variabilidad estacional y la nictímera $(P=0.144)$. 


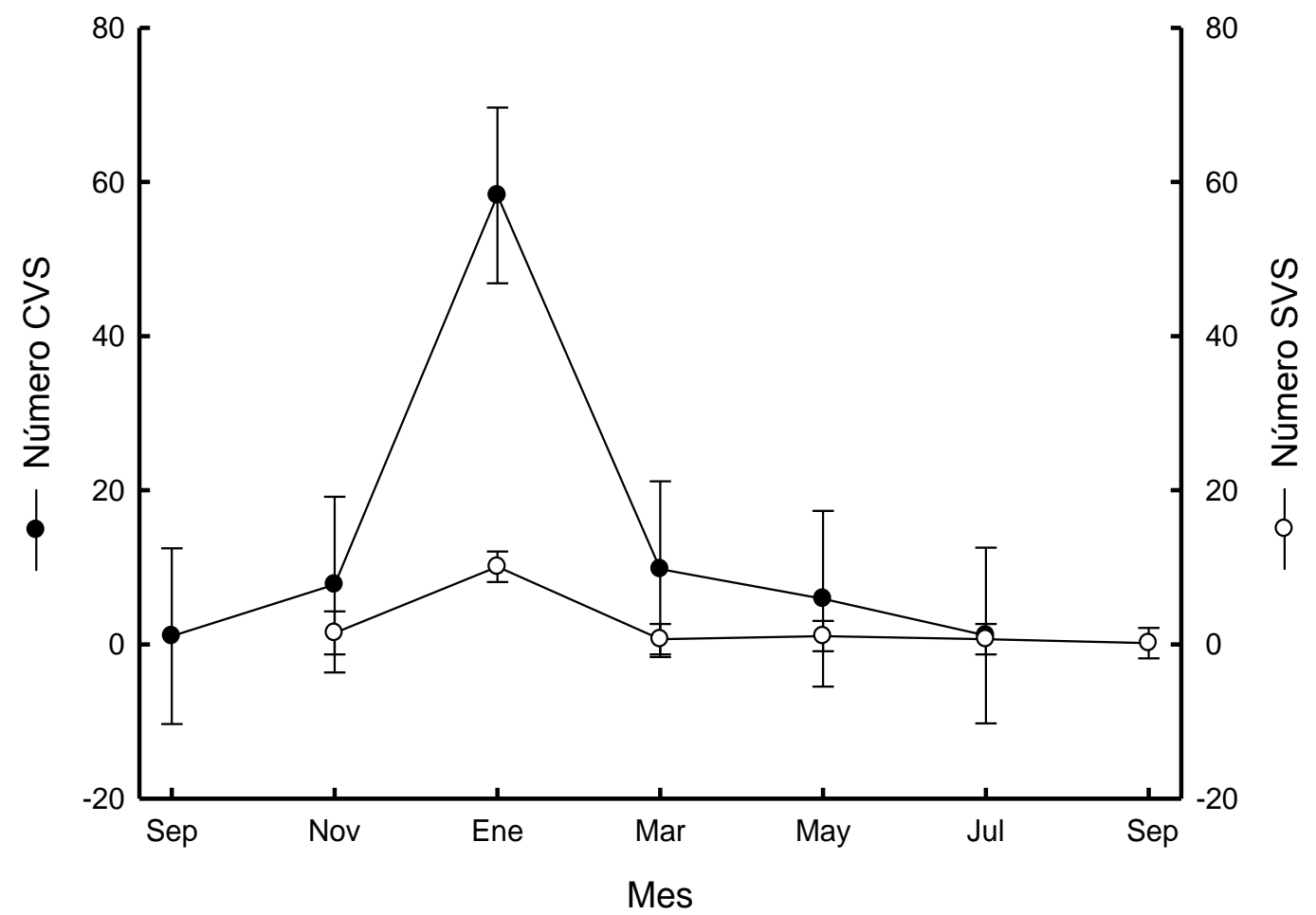

Figura 10. Promedios para cada uno de los meses de la abundancia en número de $M$. curema en el hábitat con vegetación sumergida (•CVS) y en el hábitat sin vegetación sumergida (॰SVS).

\section{Análisis nictímero}

A pesar de que la abundancia promedio en número en ambos hábitats fue mayor en el día $\left(\bar{x}_{\mathrm{Cvs}}=19.71, \bar{x}_{\mathrm{Svs}}=3.05\right)$ que en la noche $\left(\bar{x}_{\mathrm{CVS}}=5.97, \bar{x}_{\mathrm{Svs}}=1.60\right)$, no existieron diferencias significativas entre estos dos períodos (Tabla 1). Sin embargo, en el hábitat con vegetación sumergida se presentó un pulso importante entre las 14:00 h y las 16:00 h, mientras que para el hábitat sin vegetación el pulso se presentó a las 14:00 h y otro a las 10:00 h (Figura 11). 


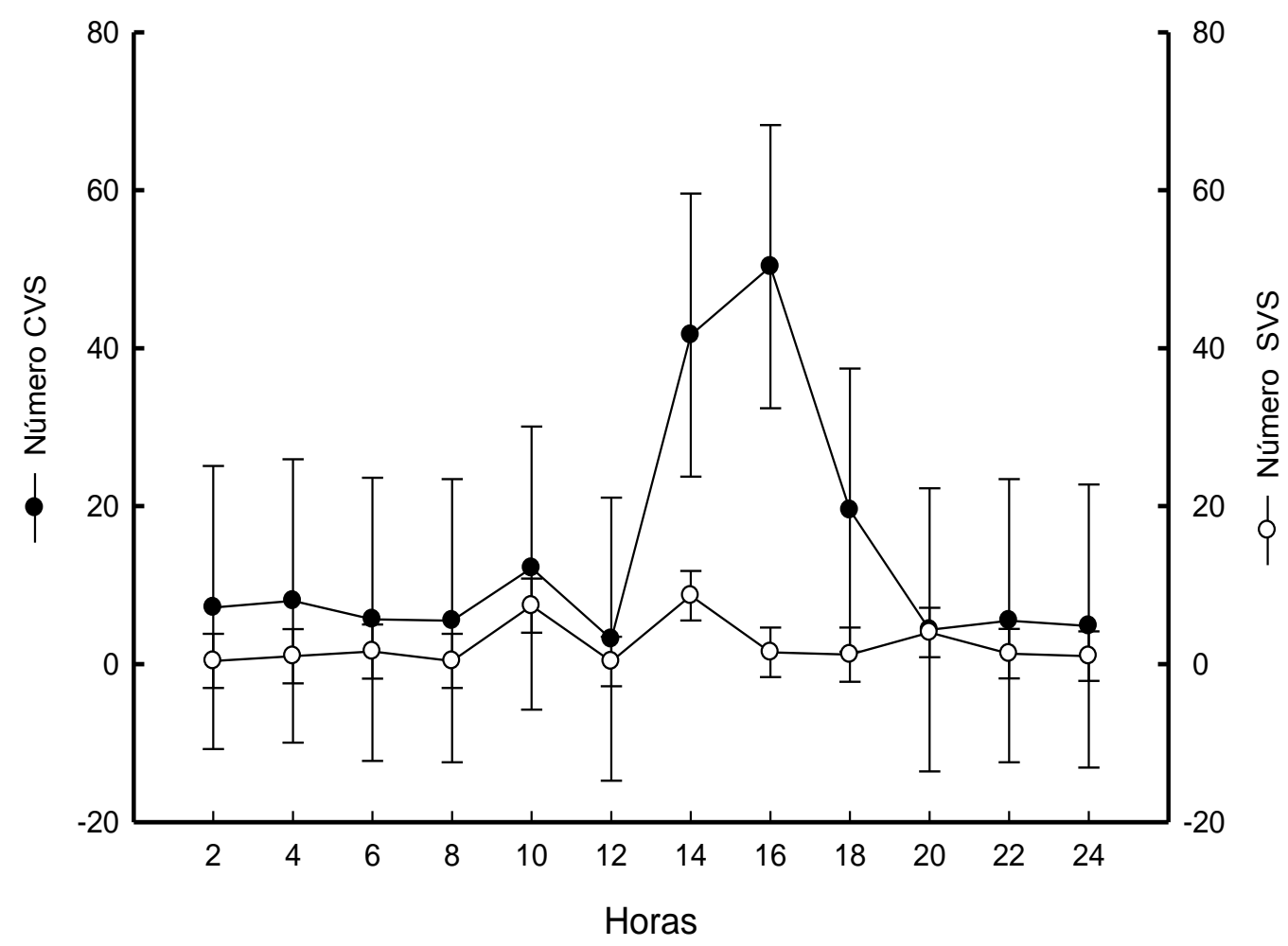

Figura 11. Promedios para cada una de las horas de la abundancia en número de $M$. curema en ambos tipos de hábitat con vegetación sumergida $(\bullet C V S)$ y en el hábitat sin vegetación sumergida $(\circ S V S)$.

\section{Influencia de las variables ambientales sobre la abundancia}

El promedio de temperatura a la que se capturó $M$. curema fue $21.7^{\circ} \mathrm{C}$, el de salinidad 17 y por último el de oxigeno $7 \mathrm{mg} / \mathrm{l}$, esto en ambos hábitats (Tabla 2). 
Tabla 2. Promedio $(\bar{x})$, desviación estándar (s), valor mínimo (Min.) y máximo (Máx.) de las condiciones ambientales (temperatura, salinidad y oxígeno) a las que fue capturada la especie Mugil curema en ambos tipos de hábitat.

\begin{tabular}{lcccc}
\hline & $\bar{x}$ & s & Min. & Max. \\
& & & & \\
\hline Temperatura & 21.7 & 3.147 & 16 & 33 \\
Salinidad & 16.98 & 3.969 & 2 & 27 \\
Oxígeno & 7.11 & 1.894 & 2 & 9 \\
& & & & \\
\hline
\end{tabular}

En el hábitat con vegetación sumergida, el mayor número de individuos se observó entre los 18 y $2^{\circ}{ }^{\circ} \mathrm{C}$, entre 16 a 18 de salinidad, y en 5 y $9 \mathrm{mg} / \mathrm{l}$ de oxígeno disuelto (Figura 12 a, b y c).

En el hábitat sin vegetación sumergida, el mayor número de individuos se apreció a los $22^{\circ} \mathrm{C}$, entre 10 a 12 de salinidad y en $5 \mathrm{mg} / \mathrm{l}$ de oxígeno disuelto (Figura 12 a, b y c). 
(a)

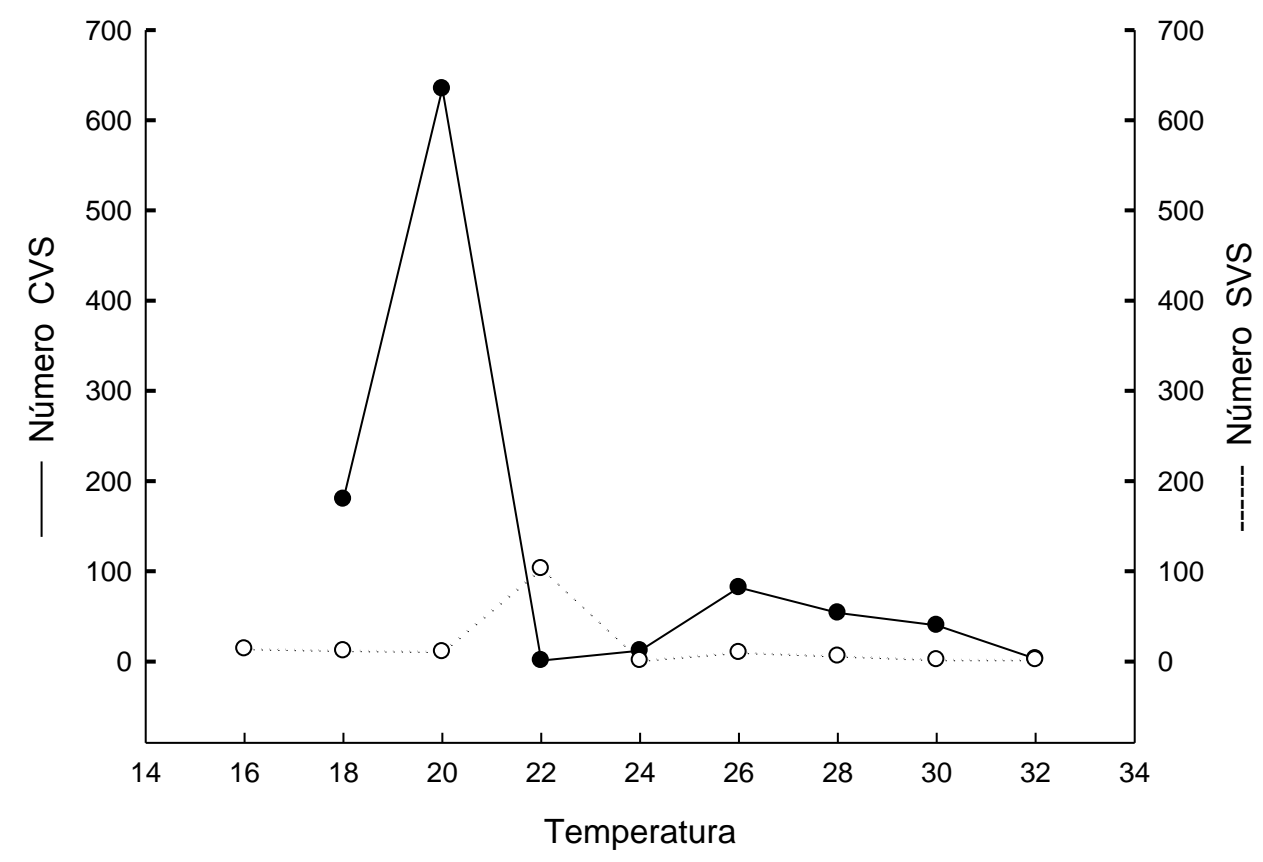

(b)

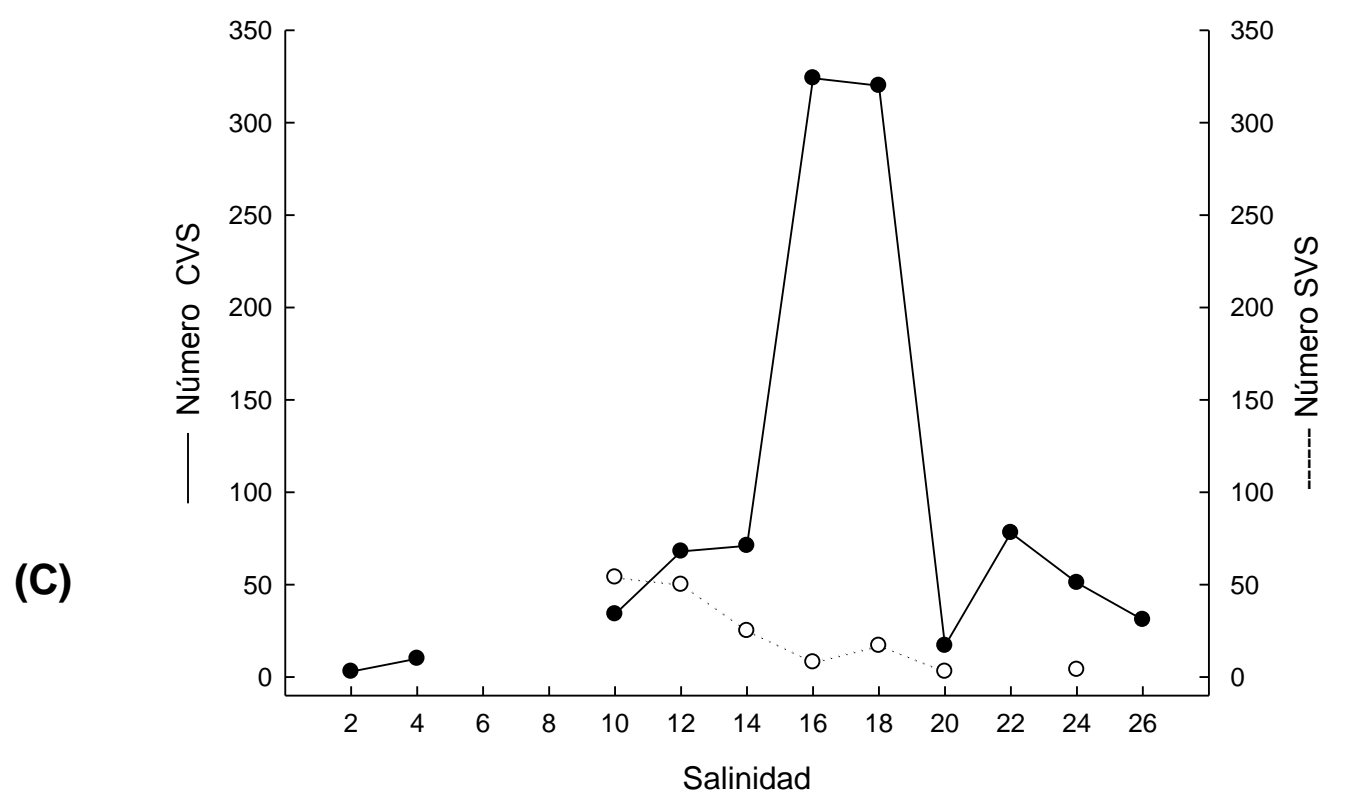




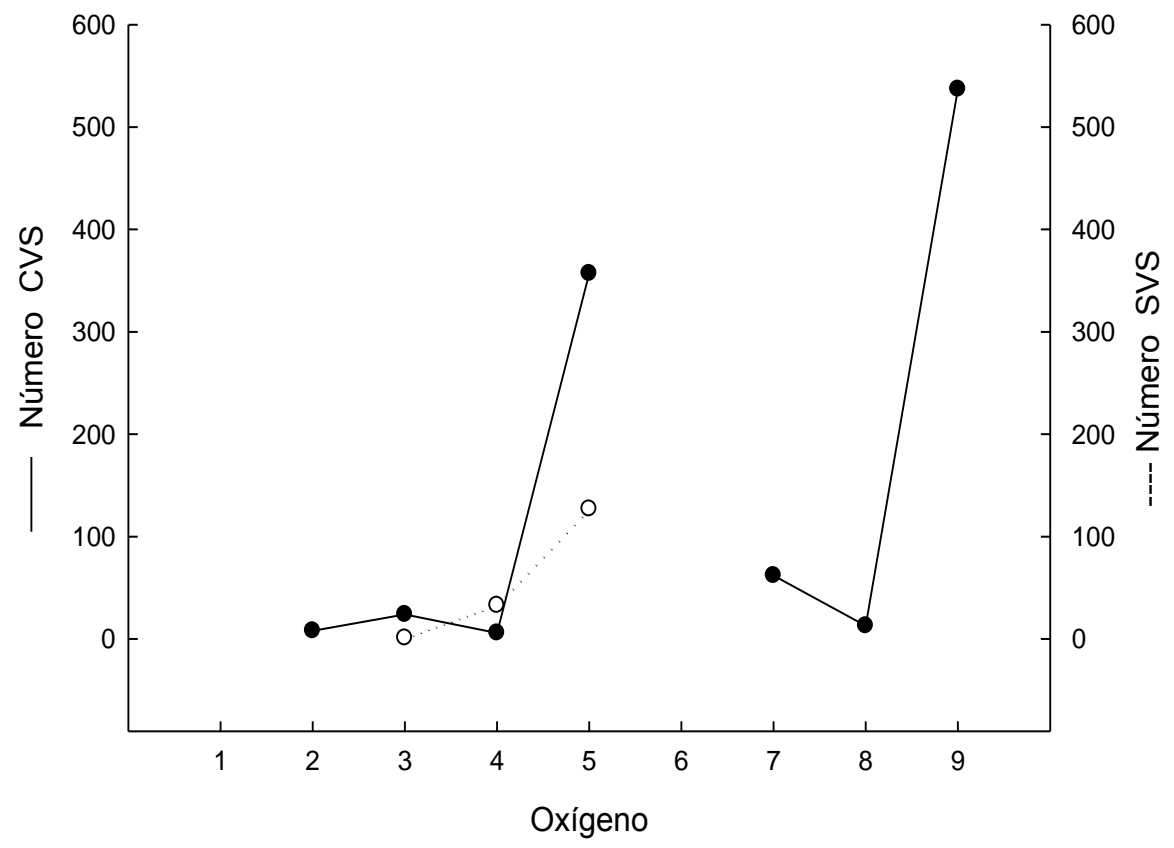

Figura 12. Preferencia de la especie por cada una de las condiciones ambientales temperatura (a), salinidad (b) y oxígeno disuelto (c) en el hábitat con vegetación sumergida (-CVS) y en el hábitat sin vegetación sumergida (---SVS).

La abundancia se correlacionó positivamente con el oxigeno disuelto y la salinidad, y negativamente con la temperatura, en el hábitat con vegetación (Tabla 3). Mientras que en el hábitat sin vegetación la abundancia solo se correlacionó positivamente con el oxigeno y negativamente con la temperatura (Tabla 4). 
Tabla 3 .Correlaciones de Spearman $\left(r_{s}\right)$ y nivel de significación $(P)$ de la abundancia en número de las principales variables ambientales, en el hábitat con vegetación sumergida.

Hábitat con

Vegetación

Temperatura

Salinidad

Oxígeno Disuelto

Número

$\mathbf{r}_{(\mathbf{s})}$

$-0.412$

0.436

0.323

$\underline{\mathbf{P}}$

0.00032

0.000127

0.0056

Tabla 4. Correlaciones de Spearman $\left(r_{\mathrm{s}}\right)$ y nivel de significación $P$ de la abundancia en número de las principales variables ambientales, en el hábitat sin vegetación sumergida.

Hábitat sin vegetación Temperatura Salinidad Oxígeno Disuelto

\section{Número}

\begin{tabular}{llll}
$\mathbf{r}_{(\mathbf{s})}$ & -0.342 & 0.193 & 0.348 \\
& & & \\
$\mathbf{P}$ & 0.0049 & 0.120 & 0.004 \\
\hline
\end{tabular}




\subsection{VARIACIÓN ESPACIO-TEMPORAL EN LA ESTRUCTURA DE LAS TALLAS Variaciones espaciales en la estructura de tallas}

Se observó que en el hábitat sin vegetación sumergida, la longitud patrón ( $\bar{x}=62.68$ $\mathrm{mm}$ ) fue significativamente mayor (Tabla 5) que en el hábitat con vegetación sumergida $(\bar{x}=50.28 \mathrm{~mm})$.

Tabla 5. Resultados de la aplicación del ANOVA de tres factores a las tallas

\begin{tabular}{lcccrc}
\hline Origen & $\begin{array}{c}\text { Suma de } \\
\text { Cuadrados }\end{array}$ & g.l & $\begin{array}{c}\text { Cuadrados } \\
\text { Medios }\end{array}$ & F & Probabilidad \\
\hline Espacial & 31480.4229 & 1 & 31480.422 & 39.468 & 0.001 \\
Estacional & 138934.629 & 5 & 27786.925 & 34.837 & 0.001 \\
Nictímero & 822.024 & 1 & 822.02439 & 1.030 & 0.3 \\
Espacial/estacional & 55886.132 & 5 & 11177.226 & 14.013 & 0.001 \\
Espacial/nictímero & 363.340 & 1 & 363.340 & 0.45553152 & 0.5 \\
Estacional/nictímero & 5359.387 & 5 & 1071.877 & 1.34384811 & 0.2 \\
Error & 898117.943 & 1126 & 797.618 & & \\
Total & 4637694.2 & 1149 & & & \\
\hline
\end{tabular}




\section{Variaciones estacionales en la estructura de tallas}

El promedio de tallas entre meses presentó diferencias significativas (Tabla 5). El comportamiento mensual de la estructura de tallas fue relativamente similar en ambos ambientes, siendo en el mes de enero en el que se observan las menores tallas (Figura 13), lo cual coincide con el mayor número de individuos observado durante este mes (Figura 10). Sin embargo, en el hábitat con vegetación las mayores tallas se observaron en noviembre y en septiembre en el hábitat sin vegetación, lo que en parte explica la interacción significativa entre los factores estacional y espacial.

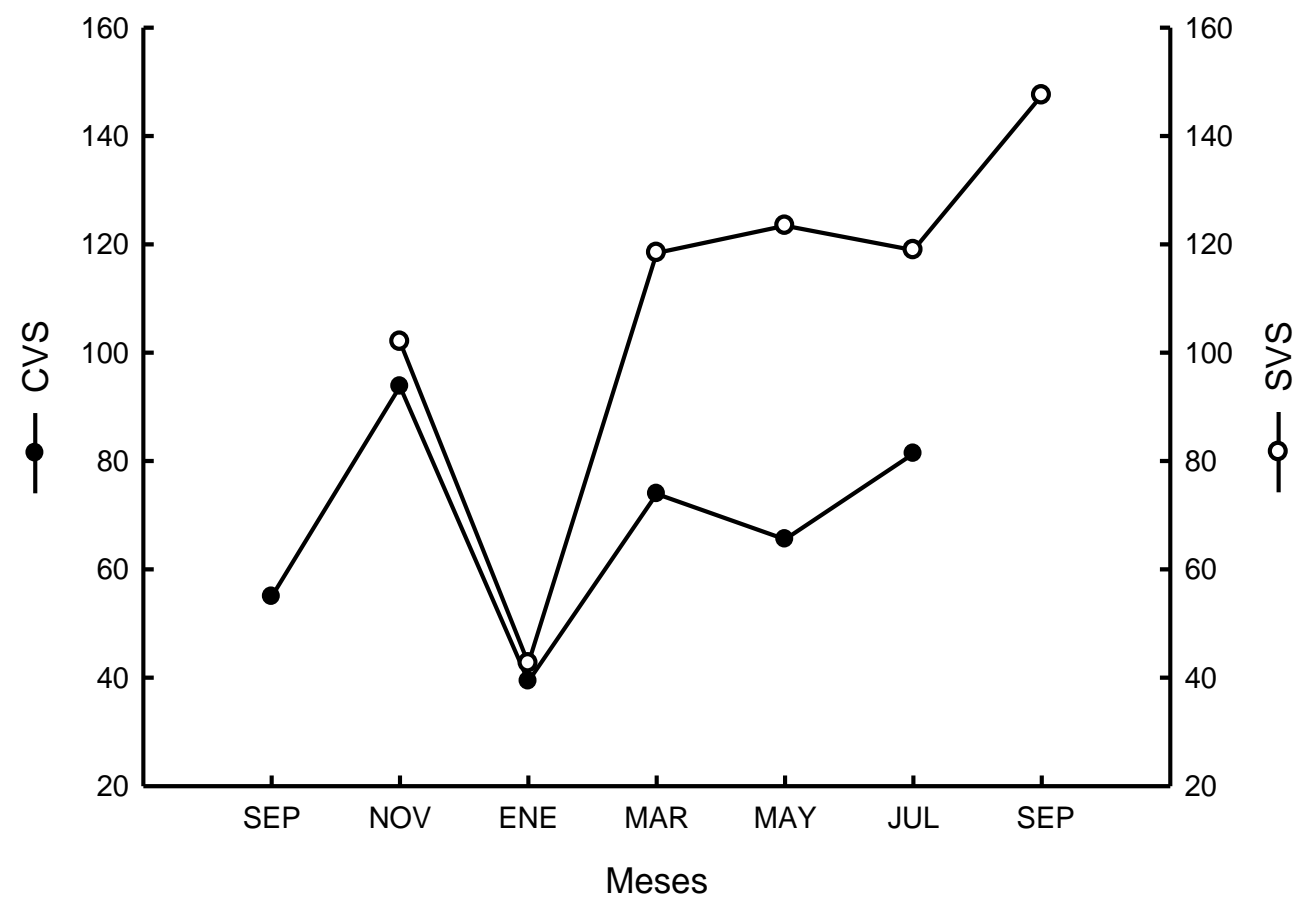

Figura 13. Variación estacional de los promedios mensuales de las tallas de los organismos capturados de la especie M. curema para los dos tipos de hábitat. 


\section{Variaciones nictímeras en la estructura de tallas}

En el hábitat con vegetación los individuos de mayor talla presentaron pulsos importantes durante horas de oscuridad (noche y penumbra), mientras que en el otro hábitat, dos de los tres pulsos importantes fueron en la noche y uno durante el día (Fig. 14), el cual estuvo representado por solo 2 individuos. Así, a nivel nictímero se observó que independiente de la localidad, generalmente los individuos más pequeños se colectaron durante el día (con vegetación $\bar{x}_{\mathrm{d}}=43.49 ; \bar{x}_{\mathrm{n}}=82.90 ; \sin$ vegetación $\left.\bar{x}_{\mathrm{d}}=56.79 ; \bar{x}_{\mathrm{n}}=89.55\right)$. No obstante lo anterior, los promedios entre día y noche no presentaron diferencias significativas.

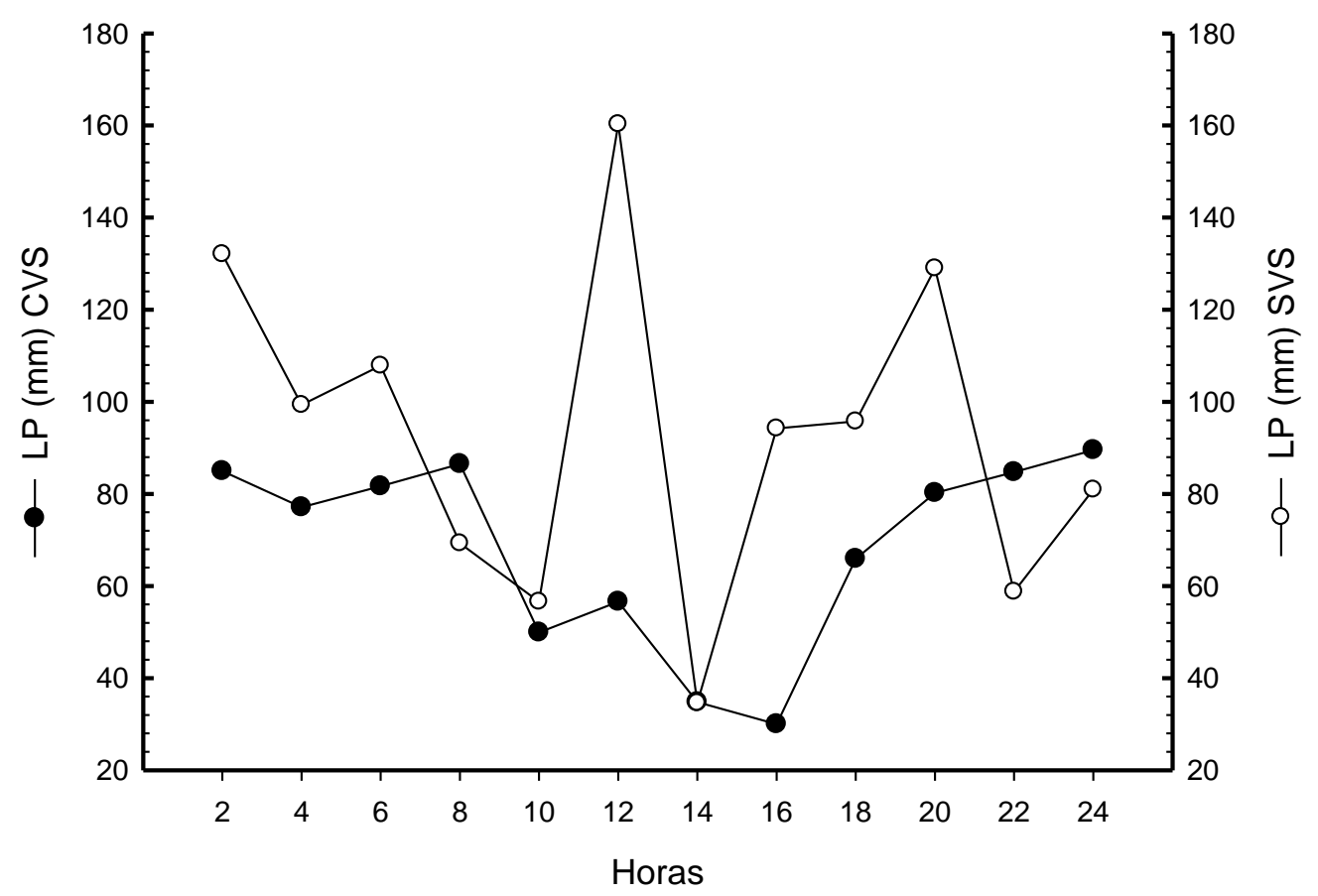

Figura14. Variación de los promedios por hora de talla de los organismos capturados de la especie $M$. curema para los dos tipos de hábitat 


\subsection{DETERMINACIÓN DE LA EDAD (MÉTODO DIRECTO)}

\subsubsection{Selección y extracción de otolitos}

A partir del análisis de la distribución de tallas (LP) por medio del diagrama de tallo y hoja, se observó una distribución trimodal, lo que podría corresponder a tres cohortes (Figura 15). Sobre la base de este análisis se procedió a la extracción de otolitos procurando tener representado cada de una de las modas de la distribución de la talla. Las tallas de los organismo seleccionados se muestran en la Figura 16. Así, se procesaron 50 individuos del hábitat con vegetación sumergida, de los cuales solo en 28 se contó con ambos otolitos; de los 22 individuos restantes, se dispuso de solo un otolito, debido a que en algunos casos éstos estaban en mal estado o se estropearon durante la manipulación. Del hábitat sin vegetación se procesaron 35 individuos, de los cuales solo en 20 se cuentó con ambos otolitos, de los 15 individuos restantes, se dispuso de un solo otolito, por las mismas razones anteriormente expuestas.
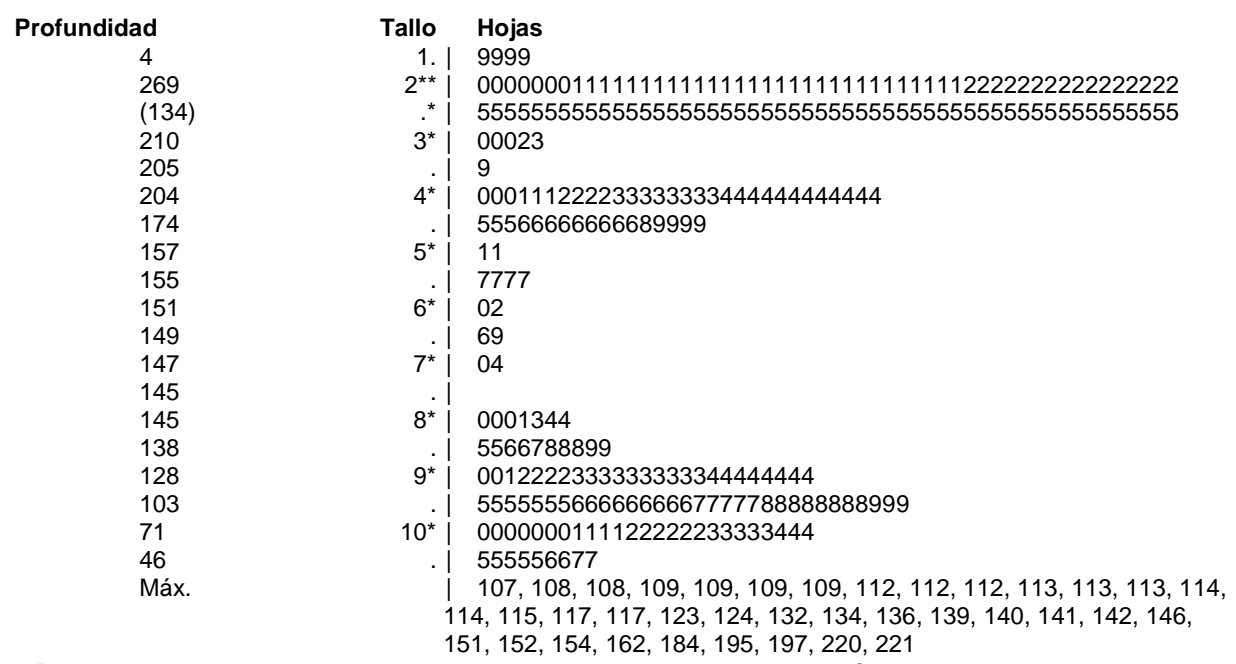

Figura 15. Diagrama de tallo y hoja de la longitud patrón de todos los individuos capturados. 

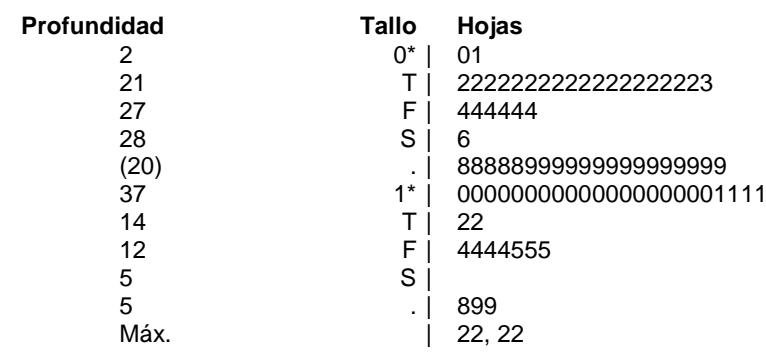

Figura 16. Diagrama de la longitud patrón de los individuos a los que se les extrajeron los otolitos.

En el presente trabajo las estructuras se prepararon y examinaron por técnicas diferentes, y con el fin de observar marcas de crecimiento, se procesaron de cada grupo de talla modal, otolitos tomados al azar. Aunque en algunas muestras se evidenciaron las líneas, éstas no fueron lo suficientemente claras para poder distinguirlas entre líneas verdaderas y falsas. Además, muchos de los otolitos estaban dañados en sus márgenes, dificultando esto la interpretación de las últimas líneas. Por estas razones se decidió no continuar con este método y se decidió hacer la estimación del crecimiento exclusivamente a través de los métodos indirectos. No obstante lo anterior, se reporta la descripción de los otolitos, así como algunos análisis de la forma de los mismos.

\subsubsection{Descripción del otolito}

El perfil de la cara interna es de forma cóncava. El otolito presentó forma alargada con margen irregular, sulco acústico con forma homosulcoidal, rostro y antirostro, cisura ausente, concentraciones calcáreas ausentes (Figura 17). 


\section{Anti rostro}

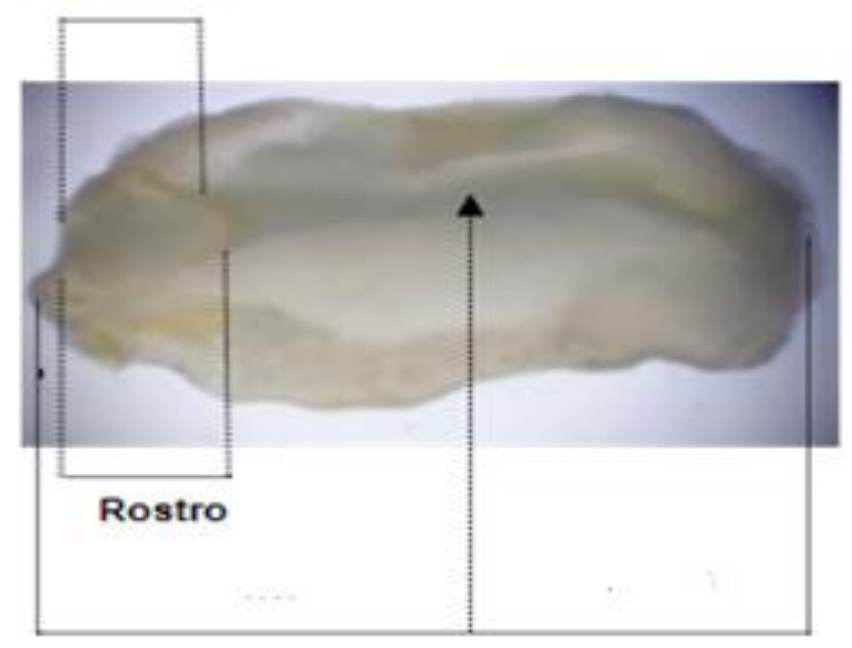

Surco acústico

Figura 17. Otolito sagita y las características morfológicas relevantes.

\subsubsection{Comparación entre la longitud y el ancho del otolito derecho e izquierdo}

Ya que no se cumplió con el supuesto de normalidad, se procedió a realizar una prueba de Wilcoxon, los promedios de la longitud del otolito derecho $(\bar{x}=4.209)$ e izquierdo ( $\bar{x}=4.210)$, así como el ancho del otolito derecho $(\bar{x}=2.078)$ e izquierdo $(\bar{x}$ $=2.096)$, no mostraron diferencias significativas $(z=0.638, p=0.527$ y $z=1.530$, $\mathrm{p}=0.125$, respectivamente).

\subsubsection{Relación longitud patrón-peso}

Para los individuos que se les extrajo otolitos, la pendiente de la relación talla-peso, fue significativamente menor a $3(b=2.74 ; t=-2.73, g l=83, p=0.008)$, lo que indica un mayor crecimiento en longitud que en peso. Los organismos capturados en el hábitat con vegetación sumergida (CVS) presentaron un crecimiento relativo en peso isométrico $(b=2.99 ; t=-0.175, g l=33, p=0.862)$ y los del hábitat sin vegetación 
sumergida (SVS) presentaron una alometría negativa $(b=2.61$; $t=-2.61, g l=48$, $\mathrm{p}=0.012)($ Tabla 6$)$.

Tabla 6. Constantes de la relación talla (longitud patrón)-peso, de los organismos de ambos hábitat (CVS: con vegetación sumergida y SVS: sin vegetación sumergida) y sin separar ambos ambientes. Se señalan: ordenada al origen (a), pendiente (b), error estándar de la pendiente (Sb), estadístico de prueba para la pendiente $(\mathrm{t})$ grados de libertad (g.I), probabilidad $(\mathrm{P})$ y tipo de alometría

\begin{tabular}{lccccccc}
\hline Hábitat & $\mathbf{a}$ & $\mathbf{B}$ & $\mathbf{s b}$ & $\mathbf{t}$ & $\mathbf{g l}$ & $\mathbf{P}$ & Alometría \\
\hline C.V.S & -4.72 & 2.99 & 0.057 & -0.175 & 33 & 0.862 & Isométrico \\
S.V.S & -4.03 & 2.61 & 0.15 & -2.61 & 48 & 0.012 & Negativa \\
General & -4.27 & 2.74 & 0.096 & -2.73 & 83 & 0.008 & Negativa \\
\hline
\end{tabular}

\subsubsection{Relación longitud patrón (LP) longitud del otolito}

El análisis de la relación alométrica entre la LP de los organismos y la longitud de los otolitos, mostró ser isométrica $(b=0.904 ; \mathrm{t}=-1.846, \mathrm{gl}=83, \mathrm{p}=0.068)$, para los organismos de ambas localidades. El crecimiento isométrico indica que el crecimiento en longitud del organismo y la longitud del otolito se mantienen constantes a través de su desarrollo. El análisis por localidad mostró diferencias en dicha relación, en el hábitat CVS mostró un crecimiento isométrico $\quad(b=0.948 ; t=-0.5$, 
g.l=33, $p=0.620$ ), mientras que la de los organismos del hábitat SVS, el tipo de relación fue alometríca negativa $(b=0.876 ; \mathrm{t}=-2.21, \mathrm{~g}=48, \mathrm{p}=0.032)$ (Tabla 7$)$.

Tabla 7. Constantes de la relación longitud patrón-longitud del otolito, de los organismos de ambos hábitat (CVS: con vegetación sumergida y SVS: sin vegetación sumergida) y sin separar por hábitat, se señalan: ordenada al origen (a), pendiente (b), error estándar de la pendiente (Sb), estadístico de prueba para la pendiente (t) grados de libertad (g.l), probabilidad (P) y tipo de alometría.

\begin{tabular}{cccccccl}
\hline Hábitat & $\mathbf{a}$ & $\mathbf{b}$ & $\mathbf{S b}$ & $\mathbf{t}$ & $\mathbf{g . I}$ & $\mathbf{P}$ & Alometría \\
\hline C.V.S & -1.272 & 0.948 & 0.104 & -0.5 & 33 & 0.620 & Isométrico \\
S.V.S & -1.1123 & 0.876 & 0.056 & -2.21 & 48 & 0.032 & Negativa \\
General & -1.1773 & 0.904 & 0.052 & -1.846 & 83 & 0.068 & Isométrico \\
\hline
\end{tabular}

\subsubsection{Relación longitud patrón (LP)- ancho del otolito}

En los individuos a los que se les extrajo otolitos, la pendiente de la relación de las variables LP y ancho del otolito, mostró un crecimiento alométrico negativo, lo que indica que el crecimiento en longitud del organismo fue mayor que el crecimiento de el ancho del otolito $\left(b=0.726 ; t=-8.838, g l=83, p=1.378 \times 10^{-13}\right)$. Dicho análisis se realizó por separado para los organismos que pertenecen al hábitat con vegetación (CVS), presentado una alometría negativa $\left(b=0.779 ; t=-5.39, g l=33, p=5.834 \times 10^{-06}\right)$ y para los individuos del hábitat sin vegetación sumergida (SVS), cuyo crecimiento fue alométrico negativo $\left(b=0.701 ; t=-6.953, g l=48, p=8.681 \times 10^{-09}\right)$ (Tabla 8). 
Tabla 8. Constantes de la relación talla (longitud patrón)-peso, de los organismos de ambos hábitat (CVS: con vegetación sumergida y SVS: sin vegetación sumergida) y sin separar ambos ambientes. Se señalan: ordenada al origen (a), pendiente (b), error estándar de la pendiente (Sb), estadístico de prueba para la pendiente $(\mathrm{t})$, grados de libertad $(\mathrm{gl})$, probabilidad $(\mathrm{P})$ y tipo de alometría.

\begin{tabular}{lccccccc}
\hline Hábitat & a & B & sb & T & gl & P & alometría \\
\hline C.V & -1.2 & 0.779 & 0.041 & -5.39 & 33 & 0.001 & Negativa \\
S.V & -1.066 & 0.701 & 0.043 & -6.953 & 48 & 0.001 & Negativa \\
General & -1.11 & 0.726 & 0.031 & -8.838 & 83 & 0.001 & Negativa \\
\hline
\end{tabular}

\subsection{Distribución de frecuencias de tallas (Método indirecto)}

\subsubsection{Análisis de la estructura de talla}

De los individuos capturados en ambos tipos de hábitat (con y sin vegetación), se midió la longitud patrón $(\mathrm{mm})$ de 1,149 organismos, el individuo de mayor talla fue de $221 \mathrm{~mm}$ mientras que el de menor de $19 \mathrm{~mm}$.

En el histograma de la distribución de frecuencias de talla (cada $5 \mathrm{~mm}$ ) (Figura 18), se observó que las longitudes entre 150 y 225 fueron menos frecuentes, mientras que las longitudes más frecuentes se encontraron alrededor de los $22 \mathrm{~mm}$. Asimismo, se observaron tres picos modales que se encuentran en los intervalos de 22-28, 47 y $96 \mathrm{~mm}$, que podrían corresponder a tres grupos de edad o cohortes. 


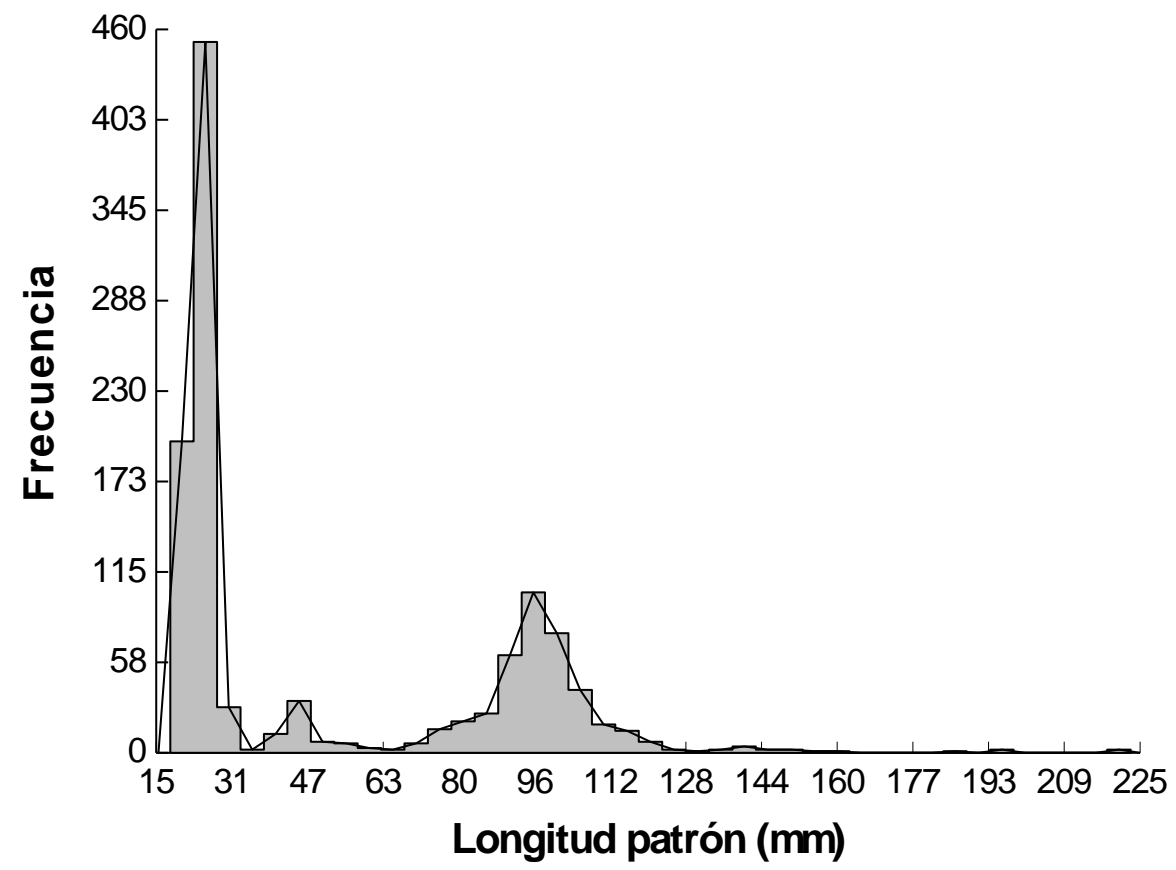

Figura 18 . Histograma de tallas (longitud patrón) de todos los organismos capturados en la laguna de Pueblo Viejo.

Mediante el Estimador de Densidad por Kernel (EDK) con función Gaussiana y ancho de banda indicada por la prueba de Silverman $(b=4)$, también se observó que el mayor número de individuos se encontró en el valor de la moda de $24 \mathrm{~mm}$ y que modas con menor número de individuos se presentaron en valores de 140.8, 184, 195. 20 y 220.80, observándose la presencia de tres picos modales, con valores de 24.00, 44.48 y $96.00 \mathrm{~mm}$ (Figura 19). 


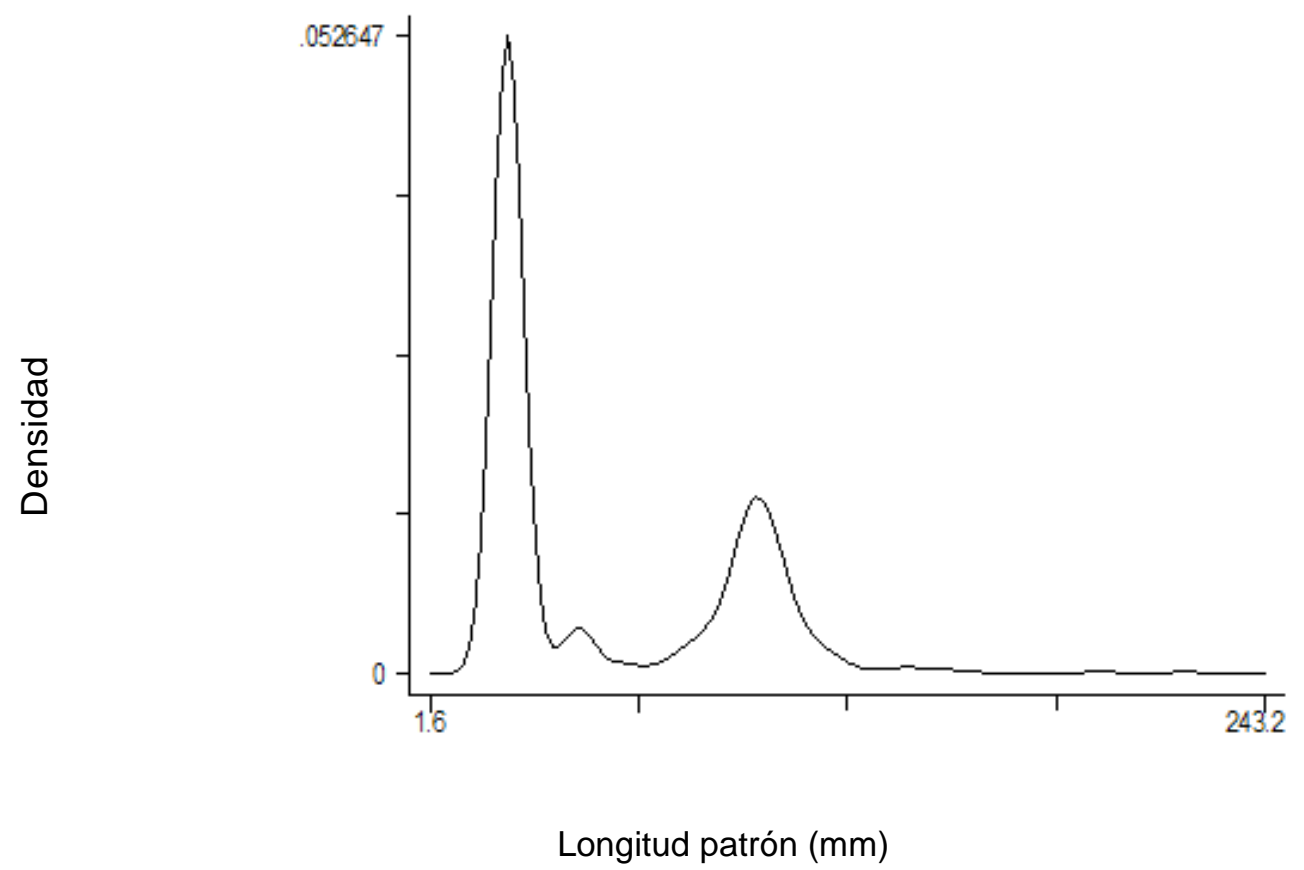

Figura 19. EDK donde se muestra la distribución total de tallas y sus grupos modales. El ancho de banda fue de $b=4$ indicado por la prueba de Silverman.

La distribución mensual de la frecuencia de tallas considerando ambos tipos de hábitats (excepto para los meses de septiembre, por ser éstos de años diferentes), está representada por el polígono de frecuencia (cada $5 \mathrm{~mm}$ ) en la Figura 20 y la Figura 21 muestra los correspondientes EDKs. Se puede observar que en ambos métodos, las tallas mínimas se presentaron en el mes de septiembre 89, enero 90 y mayo 90, lo que define períodos de reclutamiento al sistema y cohortes potenciales a lo largo del año. Mediante el uso de los EDKs (Figura 21) correspondientes a las frecuencias de talla por mes, se observa un comportamiento multimodal en el mes de mayo; bimodal en los meses de septiembre 89, enero 90, marzo 90 y julio 90; y unimodal en noviembre 90 y septiembre 90 . Algunas de las modas detectadas por este análisis, se muestran en la Tabla 9, de acuerdo con las tres cohortes 
potenciales.

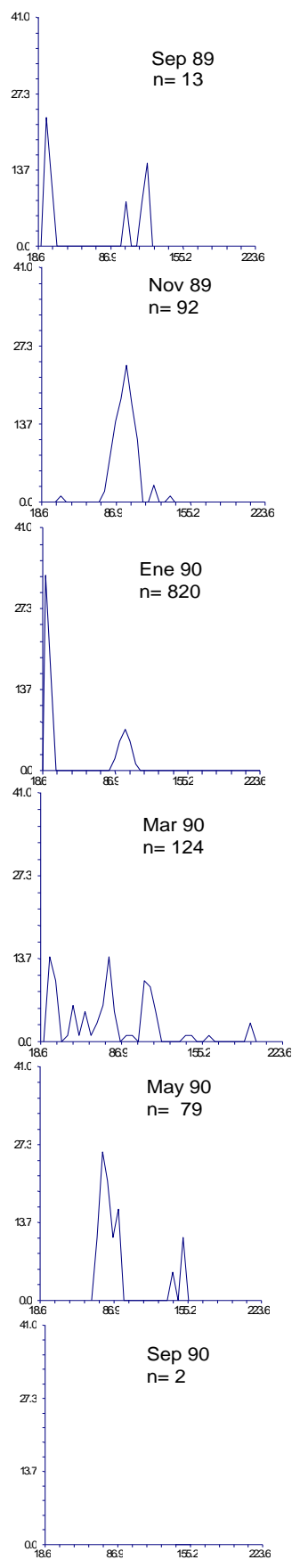

Longitud patrón ( $\mathrm{mm})$

Figura 20. Distribución de frecuencia de tallas (cada $5 \mathrm{~mm}$ ) por mes (ordenados cronológicamente), de todos los individuos de M. curema. 

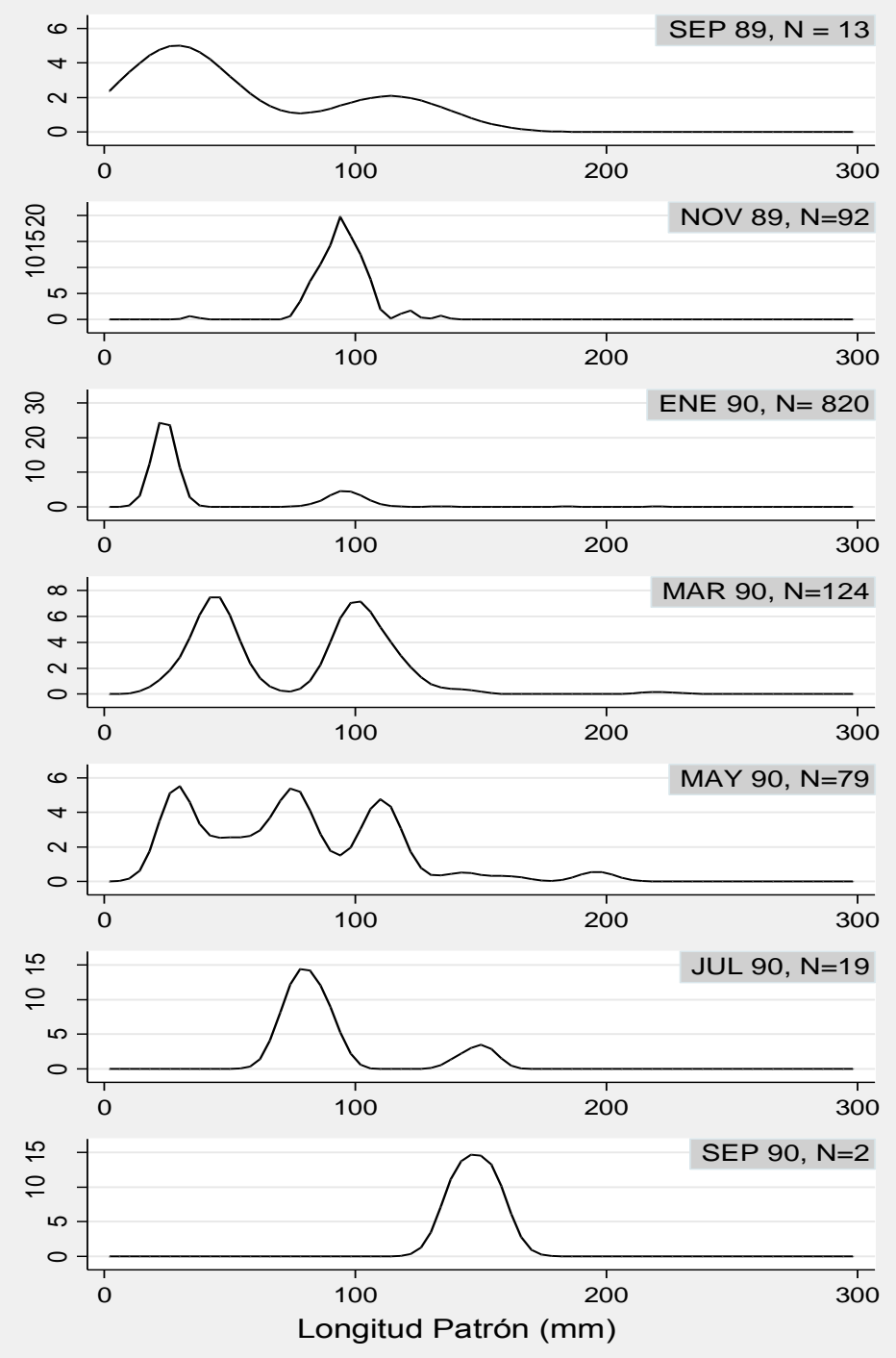

Figura 21. EDKs donde se muestra la distribución mensual de tallas (Longitud Patrón) para $M$. curema incluyendo ambos tipos de hábitats (excepto septiembre). El ancho de banda fue indicado para cada mes por la prueba de Silverman y la regla sobresuavizada de Scott (enero y julio).

De acuerdo al método que aplica el programa de ELEFAN I, se aprecia una cohorte importante (que inicia en el mes de enero). Considerando las línea de crecimiento trazada (Figura 21) partiendo de enero hasta julio (cohorte de enero), se puede 
observar cómo las modas se van recorriendo hacia valores mayores, lo que indica un aumento de talla (LP). El análisis de los datos proporcionó una estimación de $\mathrm{L}_{\infty}$ de $320 \mathrm{~mm}$ de LP y el valor de Rn fue de 0.104 para dicha cohorte.

Así, el inicio de la cohorte de enero está representado por los individuos que en este mes presentan talla menor (moda de $21.60 \mathrm{~mm}$, Tabla 9), a partir del cual los individuos van creciendo (Figura 22) hasta el mes de julio, cuando alcanzan tallas más grandes.

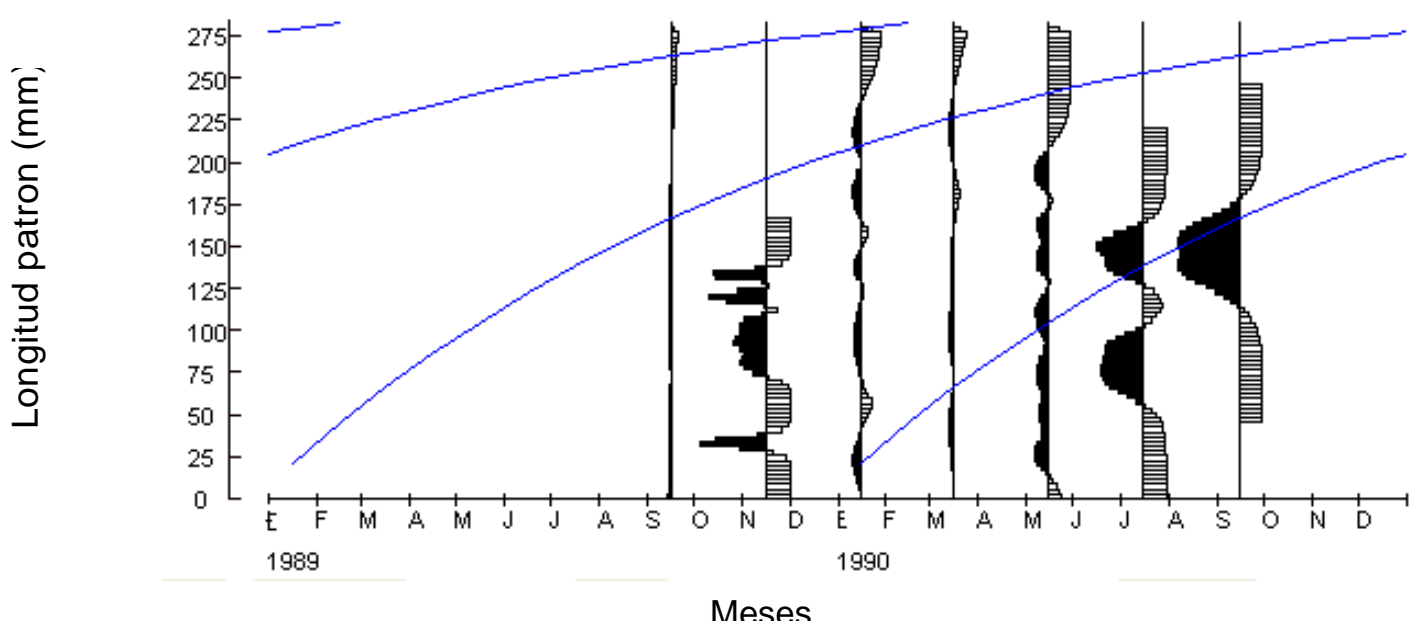

Figura 22. Curva de crecimiento estimada por la rutina ELEFAN I, Se muestra las línea de crecimiento ajustada que unen las frecuencias modales más importantes para la cohorte de enero, la cual indica el ritmo de crecimiento de la especie en el área de estudio.

Un análisis detenido de la progresión de la distribución mensual de tallas (Figura 20 y 21) y mediante el uso de los EDKs (considerando los principales valores de las modas de cada mes), permitió identificar dos cohortes más, además de la cohorte de enero (Tabla 9), las cuales empiezan en los meses de septiembre 89 y mayo 90 
(meses de reclutamiento), debido a que en estos meses aparecen los individuos más pequeños de todo el muestreo, resultado de supuestos eventos reproductivos.

Puesto que el primer grupo modal $(21.60 \mathrm{~mm})$ de enero, corresponde a organismos más pequeños y a partir de este mes los valores de las modas mensuales se desplazan hacia la derecha, conforme los organismos crecen, se observó que alcanzarían una talla de $150.14 \mathrm{~mm}$ en el mes de julio (Tabla 9), presentando un crecimiento de $128.54 \mathrm{~mm}$ en 6 meses. Comparaciones pareadas entre todas las modas de esta cohorte, revelaron un ritmo de crecimiento aproximado a $21 \mathrm{~mm}$ mes (Tabla 9).

Asimismo, considerando los individuos más pequeños de septiembre de 1989, como un grupo modal potencial de $26.44 \mathrm{~mm}$ y siguiendo el valor de las modas hasta mayo, estos alcanzarían una talla de $196 \mathrm{~mm}$, presentando un crecimiento de 170 $\mathrm{mm}$ en 8 meses. Similarmente, comparaciones pareadas entre todas las modas de esta cohorte, revelaron un ritmo de crecimiento aproximado a $22 \mathrm{~mm}$ mes (Tabla 9).

El tercer grupo modal correspondió a individuos que en mayo ( $28 \mathrm{~mm})$, los cuales alcanzarían $221.27 \mathrm{~mm}$ en marzo, lo que representaría un crecimiento aproximado de $193 \mathrm{~mm}$ en 10 meses. Las comparaciones pareadas entre todas las modas para esta cohorte, mostraron un ritmo de crecimiento aproximado a $19 \mathrm{~mm}$ mes (Tabla 9). Finalmente, para tener una representación del crecimiento de la especie en el área de estudio, se observó el seguimiento del valor de las modas de estas cohortes (Tabla 9), presentando un ritmo de crecimiento en promedio total de $21 \mathrm{~mm}$ por mes. 
Tabla 9. Se señalan valores modales (LP mm) producto del análisis EDK, de acuerdo con tres potenciales cohortes (SEPTIEMBRE, ENERO y MAYO), los promedios en crecimiento por mes $(\overline{\boldsymbol{x}})$, de acuerdo a comparaciones pareadas entre las modas de cada potencial cohorte.

\begin{tabular}{|c|c|c|c|c|c|c|c|c|c|c|c|}
\hline MES & SEP & NOV & ENE & MAR & MAY & JUL & SEP & NOV & ENE & MAR & $\bar{x}$ \\
\hline \multicolumn{12}{|l|}{ COHORTE } \\
\hline SEPTIEMBRE 89 & 26.44 & & 93.20 & 133.57 & 196.00 & & & & & & 22.14 \\
\hline ENERO 90 & & & 21.60 & & 109.20 & 150.14 & & & & & 21.26 \\
\hline MAYO 90 & & & & & 28.00 & 80.51 & & & 180.00 & 221.27 & 19.52 \\
\hline
\end{tabular}

\subsection{ASPECTOS REPRODUCTIVOS}

\subsubsection{Análisis gonádico}

En relación con el análisis gonádico, en la Tabla 10 se muestra la estadística descriptiva de la longitud patrón, peso de la gónada e índice gonadosomático de las hembras de M. curema en la laguna de Pueblo Viejo. En general, se pudo observar que los pesos de los ovarios fueron relativamente bajos, a pesar de que este análisis incluyó individuos grandes (hasta de $221 \mathrm{~mm}$ de longitud). En consecuencia los valores del IGS fueron muy bajos, lo que explica en gran parte que la población de esta especie en la Laguna de Pueblo Viejo, está constituida principalmente por individuos juveniles, en fases tempranas de maduración gonádica (Figura 23). Así, el intervalo de variación del Índice gonadosamático de las hembras $(<0.7 \%)$ evidenció una población donde predominan los individuos inmaduros. 
Tabla 10. Estadística descriptiva de la longitud patrón, peso del ovario e IGS, para las 144 hembras consideradas en el análisis gonádico.

\begin{tabular}{lcccc}
\hline Variable & Promedio & $\begin{array}{c}\text { Desviación } \\
\text { Estandár }\end{array}$ & Mínimo & Máximo \\
\hline Longitud Patrón $(\mathbf{m m})$ & 104.48 & 2.272 & 83.20 & 221.00 \\
Peso del ovario (g) & 0.041 & 0.177 & 0.0022 & 1.9848 \\
IGS & 0.091 & 0.107 & 0.0075 & 0.7292 \\
\hline
\end{tabular}

De manera general no se observó un periodo de reproducción bien definido, debido a que en el presente estudio no se encontraron gónadas categorizadas como maduras. Sin embargo, se propuso documentar la periodicidad de reproducción de acuerdo con los meses que se detectaron como periodos de reclutamiento (Tabla 9), en los cuales la población está compuesta por organismos con tallas aproximada de $20 \mathrm{~mm}$ (juveniles). Respecto a lo anterior la reproducción de la especie podría ocurrir dentro de los períodos de diciembre-enero, marzo-abril y julio-septiembre.

Asimismo, se observó una relación directa entre los valores promedios mensuales del IGS y de la longitud patrón ( $\mathrm{mm}$ ), ya que a medida que los organismos aumentan de talla se incrementa su madurez gonádica (Figura 24). 


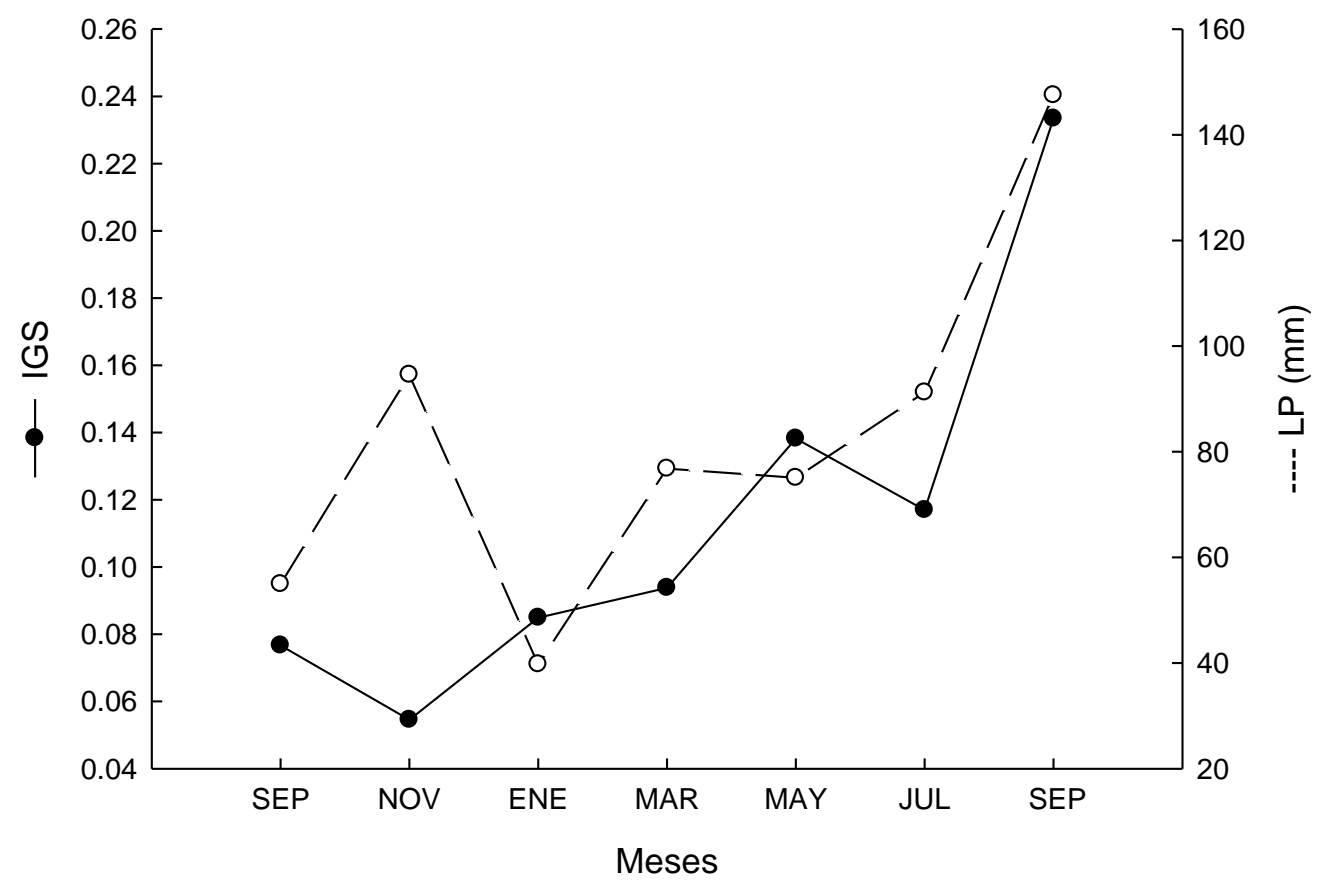

Figura 23. Variación mensual del índice

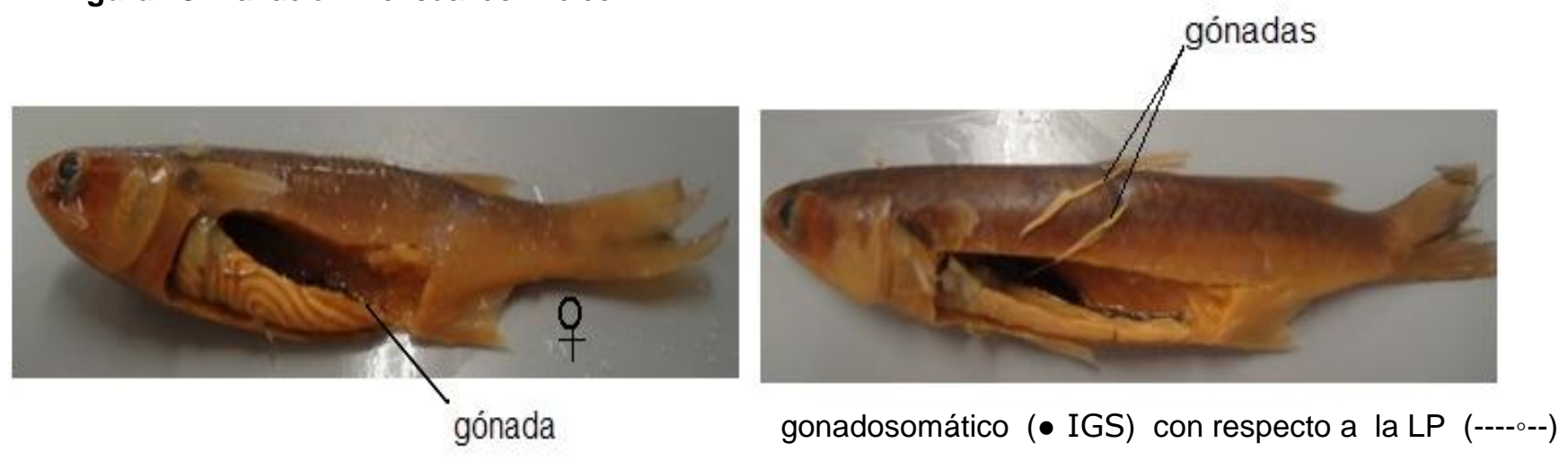

de las hembras de la especie M. curema.

Figura 24. Gónadas de hembras de M. curema. 


\section{DISCUSIÓN}

\section{DISTRIBUCIÓN Y ABUNDANCIA}

La abundancia de $M$. curema fue significativamente mayor en el hábitat con vegetación sumergida, lo cual puede deberse a que dichos ambientes son estructuralmente más complejos, lo que proporciona excelente refugio contra los depredadores, además de grandes cantidades de alimento, por lo que son utilizados como áreas de crianza, (Lubbers et al., 1990; Ross, 2003; Allen et al., 2007; Guevara et al., 2007; Unsworth et al., 2009), permitiendo así incrementar las tasas de crecimiento, reduciendo también la mortalidad (Rozas et al., 1988; Castillo-Rivera et al., 2002).

El análisis de la abundancia en número de $M$. curema presentó diferencias significativas entre meses y en ambos hábitats se observó un pulso importante en el mes de enero. Lo anterior puede deberse, a que generalmente los patrones estacionales de la abundancia de comunidades de peces en estuarios tropicales y subtropicales se relacionan con la variación de algunos factores ambientales, dentro de los cuales los más importantes han sido la temperatura y la salinidad (Kupschus \& Tremain, 2001; Jaureguizar et al., 2004). A pesar que en estudios previos se sugiere

que los juveniles y adultos de $M$. curema se encuentran más frecuentemente a temperaturas superiores a $20^{\circ} \mathrm{C}$ y a salinidades altas (Vieira, 1991), específicamente para el sistema estudiado, la abundancia de esta especie se relacionó con altas 
salinidades y con temperaturas bajas (mayores abundancias a $20^{\circ} \mathrm{C}$, Figura $12 \mathrm{a}$ ), comportamiento que ya ha sido observado por Castillo-Rivera et al. (2010).

A pesar de que la abundancia $M$. curema no varió significativamente a nivel nictímero, en ambos hábitats se observaron pulsos importantes durante el día, patrón que ya ha sido reportado en estudios previos, en los que también consideran a $M$. curema como una especie típicamente diurna (preferentemente entre las 10:00 h y las 18:00 h, Figura 11), aunque puede extender su actividad a horas del amanecer y/o anochecer (Castillo-Rivera et al., 2005; 2010). Los cambios en la abundancia de individuos en los periodos diurnos y/o nocturnos, se han atribuido a la alimentación y/o a la evasión de la depredación (Arrington \& Winemiller, 2003; Gaelzer \& Zalmon, 2008, Rocha et al., 2010).

\section{VARIACIÓN ESPACIO-TEMPORAL EN LA ESTRUCTURA DE LAS TALLAS}

La talla promedio en el hábitat sin vegetación fue significativamente mayor que en el hábitat con vegetación, lo cual ha sido atribuido principalmente al hecho de que los organismos más pequeños utilizan las zonas con vegetación para alimentarse, crecer y refugiarse de posibles depredadores (Griffiths, 2001; Aziz et al., 2006; Horinouchi, 2008; Arceo-Carranza et al., 2010).

Estacionalmente, en ambos hábitats se encontraron diferencias significativas en las tallas promedio mensuales $(P=0.001)$. En este estudio en el mes de enero se encontró el mayor número de individuos de tallas pequeñas lo que puede indicar que 
durante este mes, existe un importante pulso de reclutamiento, lo cual concuerda con lo observado por Idelberger y Greenwood (2005), estos autores encontraron que los periodos de alta abundancia coinciden con el periodo de longitud promedio más bajo reflejando periodos de reclutamiento. Al comparar los resultados obtenidos por otros autores, Vieira (1991) reportó un proceso de reclutamiento en enero, Ibáñez- Aguirre et al. (1995) en el mes julio y Marin \& Quintero (2003) lo reporta para los meses de marzo y junio. Las variaciones en el tiempo de reclutamiento han sido asociadas a la disponibilidad de alimento y condiciones necesarias (producción primaria y mecanismos hidrográficos) para el crecimiento, desarrollo y supervivencia de los juveniles (Vieira, 1991, Castillo-Rivera et al., 2001, Marín \& Quintero., 2003).

En cuanto al comportamiento nictímero de la distribución de tallas de la especie, se observó que independiente de la localidad y el mes analizado, los individuos más pequeños se recolectaron durante el día, aunque sin mostrar diferencias significativas entre el día y noche. La mayor proporción de individuos pequeños suele atribuirse a la actividad alimentaria, lo que hace que todas las tallas estén disponibles tanto en el día como la noche (Duarte et al, 2006). De hecho, los cambios nictímeros están basados en la estructura trófica de los peces, estos cambios han estado estructurados por factores tales como la disponibilidad de alimento y el suministro de refugio (Unsworth et al., 2007). 


\section{DETERMINACIÓN DE LA EDAD (MÉTODO DIRECTO)}

Para utilizar cualquier estructura en la determinación de la edad, es necesario comprobar que las marcas reflejen las variaciones periódicas de las tasas de crecimiento. Se considera que la determinación de la edad de los peces tropicales es más difícil que en los peces de aguas templadas, ya que éstos suelen presentar marcas que no necesariamente son de crecimiento y que deben distinguirse de las que se forman a intervalos de tiempo regulares (Rocha-Olivares \& Gómez-Muñoz, 1993).

Ibañez-Aguirre y Gallardo-Cabello (1996) concluyen que para los mugílidos de zonas frías y templadas, las variaciones de temperatura debidas a la estacionalidad son la causa fundamental de la formación de las marcas. En los trópicos, por la estabilidad de la temperatura, no se tienden a formar líneas estacionales. En otros casos, las marcas pueden estar asociadas con otros factores como son las lluvias, la abundancia o escasez de alimento o factores internos como el desove.

Estudios realizados han señalado que la formación de las marcas de crecimiento de especies tropicales ha sido relacionada con la actividad reproductiva (Rocha-Olivares \& Gómez-Muñoz, 1993). Sin embargo, se ha observado en otras especies de peces tropicales, que la formación de los annulli no son necesariamente consecuencia directa de la actividad reproductora. Por otra parte, los anillos formados en los peces tropicales y la interpretación del patrón de formación se ve enmascarada por la presencia de anillos falsos (Morales- Nin et al., 1991; Weatherley, 1987). Asimismo, 
estudios previos han sugerido que el manejo y el almacenamiento prolongado de los otolitos pueden influir en la composición de los mismos (Hedges et al., 2004). Lai (1985) y Morales-Nin (1991) encontraron que los otolitos no pueden guardarse en una solución de alcohol porque éstos se disuelven con el tiempo. También mencionan que el formol se ha usado para conservar los otolitos, pero esto no lo recomiendan porque el formol causa la degradación de los mismos. La disolución de los otolitos en los medios de almacenamiento puede ser un problema durante la preservación de las muestras. En el presente estudio, los otolitos de la especie no se extrajeron inmediatamente, por el contrario los peces permanecieron fijados y almacenados por mucho tiempo en alcohol al extraerse los otolitos, algunos se encontraron degradados. Así que la conservación de los individuos en el medio de almacenamiento y la preservación durante mucho tiempo pudo tener un efecto sobre la identificación y determinación de las marcas de crecimiento. Este hecho se puede considerar como uno de los factores que implicó la pérdida y/o la falta de observación definida de las marcas de crecimiento. En este sentido, Morales-Nin (1991) concluye que las marcas de crecimiento son más visibles en los otolitos recién colectados y éstas deben leerse a la mayor brevedad posible. Por lo tanto los otolitos deben extraerse y leerse inmediatamente después de la muerte del pez.

Otro factor que pudo afectar la definición de marcas de crecimiento, reside en los patrones de historia de vida intrínsecos a la especie. Como han señalado algunos autores (Brothers, 1987 \& Morales-Nin, 1991), la formación de marcas de crecimiento 
está relacionada con cambios estacionales en diferentes factores (temperatura, lluvias, desove, etc.). La variabilidad estacional de estos factores se alcanza plenamente a lo largo de un año. En este sentido, Anderson (1957) señala que en el primer año de vida, la especie Mugil curema alcanza tallas de $200 \mathrm{~mm}$. En el presente estudio, el $99.8 \%$ de los individuos capturados fue menor o igual a $200 \mathrm{~mm}$ de LP, por lo que se puede considerar que la mayoría de los individuos colectados tienen menos de un año de vida. Así, los cambios estacionales de los factores ambientales, no alcanzaron a presentar una oscilación marcada que permitiera la formación de anillos.

Debido a que no se encontraron diferencias significativas en el largo y ancho de los otolitos de cada lado (izquierdo y derecho) de M. curema, ambos pueden utilizarse indistintamente. Por otra parte, se observó que conforme el pez envejece los otolitos aumentan de grosor y se curvan.

La alometría observada en la relación talla del pez-crecimiento otolito, puede ser reflejo de que la tasa de crecimiento sea la diferencia entre las tasas de crecimiento de los otolitos y de los peces, la confiabilidad de la determinación de la edad disminuirá para las edades mayores. En el caso de las relaciones estudiadas, el grado de alometría está dado por la magnitud del exponente de la relación multiplicativa. 


\section{DISTRIBUCIÓN DE FRECUENCIAS DE TALLAS (MÉTODO INDIRECTO)}

En relación con los intervalos de talla que presenta $M$. curema en diferentes sistemas, para la Laguna de Tamiahua, Veracruz, Ibañez-Aguirre et al. (1995; 1999) encontraron un intervalo de 160 a $340 \mathrm{~mm}$ de longitud total; Salomon y Ramnarine (2007) reportan un intervalo de 260 a $405 \mathrm{~mm}$ de longitud total en el Golfo de Paria, Trinidad; y Anderson (1957) en la costa del Atlántico Sur de EE.UU reporta un promedio de longitud patrón (LP) de $350 \mathrm{~mm}$. El intervalo de talla encontrado en el presente estudio fue de 19 a $221 \mathrm{~mm}$, con valores modales entre $22-28 \mathrm{~mm}, 37-50$ $\mathrm{mm}$ y a $90 \mathrm{~mm}$, siendo poco comunes los individuos con tallas mayores a los 160 $\mathrm{mm}$. Esto indica que en la laguna de Pueblo Viejo, la población de $M$. curema se encuentra representada principalmente por juveniles (individuos de talla pequeña).

De a cuerdo con los polígonos y los EDKs correspondientes a las frecuencias de tallas por mes, se observa que en la zona de estudio, las tallas menores se presentaron el mes de septiembre 89 , enero 90 y mayo 90 , detectándose como periodos de reclutamiento. En cambio en la laguna de Tamiahua, Veracruz, IbáñezAguirre et al. (1995) por medio de la aplicación de los métodos de Petersen, Cassie y Battacharya, reportaron las tallas mínimas en los meses de febrero (1992) y julio (1991), señalándolos como meses de nacimiento y de reclutamiento biológico.

Considerando los meses de enero, mayo y septiembre cuando se presentaron las tallas más pequeñas y observando la progresión modal de tallas de los organismos (utilizando los principales valores de las modas de cada mes), se observa que de enero a julio, mayo-marzo y septiembre-mayo se tiene un ritmo de crecimiento 
aproximado de $21 \mathrm{~mm}$ por mes en sus primeros estadios de desarrollo (hasta los 160 mm). Para esta especie, Anderson (1957) registró que el crecimiento fue de $17 \mathrm{~mm}$ por mes, en la costa del Atlántico Sur de EE.UU., esta población reside en aguas templadas, esperaría que los organismos presentaran un crecimiento más lento que en aguas tropicales.

De acuerdo con lo anterior, se puede concluir que los organismos de esta especie utilizan la laguna, particularmente el hábitat con vegetación sumergida, como área de protección y crianza, ingresando al sistema individuos de tallas pequeñas ( 20mm), los cuales y permanecen en el mismo, alrededor de siete meses, tiempo durante el cual alcanzan una talla aproximada de $160 \mathrm{~mm}$.

Es importante mencionar que el uso de estimadores de la densidad, ofrece la posibilidad de mostrar los valores modales, que no pueden ser identificados mediante histogramas tradicionales con intervalos de clase convencionales (AyalaPérez et al., 2006). Así, los resultados obtenidos demuestran las ventajas que puede representar el empleo del método de análisis de distribución de frecuencias de tallas de $M$. curema mediante EDKs, los cuales eliminan la subjetividad al seleccionar el origen y la amplitud de banda (intervalo), existiendo un respaldo estadístico objetivo para la amplitud de banda utilizada (Salgado-Ugarte et al., 1993, 1994, 1995a, 1995b)

En cuanto a los parámetros de crecimiento obtenidos en este estudio por medio del método indirecto de ELEFAN I, se determinó que la especie alcanza una $L_{\infty}$ de 320 mm (cohorte enero). Para esta misma especie lbañez-Aguirre et al. (1995) 
registraron una $L_{\infty}$ de 400.3 (escamas) y $461.4 \mathrm{~mm}$ (otolitos) en Tamiahua, Veracruz. Asimismo en trabajos realizados en otros estados, las longitudes asintóticas obtenidas (Michoacán, $L_{\infty}=472 \mathrm{~mm}$; Colima, $\mathrm{L}_{\infty}=482 \mathrm{~mm}$; Meléndez-Galicia \& Romero-Acosta, 2010; Cabral-Solís, 1999), también fueron mayores a las estimadas en el presente estudio. Estas diferencias pueden ser explicadas por el hecho de que en la laguna de Pueblo Viejo, la estructura de tallas de los individuos de esta especie, está principalmente representada por individuos inmaduros de talla pequeña, lo que genera una estimación de $L_{\infty}$ de menor magnitud, que la reportada en otros estudios.

\section{ASPECTOS REPRODUCTIVOS}

\section{Análisis gonádico}

En relación con los aspectos reproductivos, se observó que la especie $M$. curema no se reproduce dentro de laguna de Pueblo Viejo, debido a que en el análisis de las gónadas no se encontraron organismos maduros. Los ovarios analizados fueron muy pequeños. Lo anterior sugiere que la especie ocupa el sistema para desarrollar etapas tempranas de su ciclo de vida, utilizándolo como zona de crianza, crecimiento y maduración.

Los periodos de reproducción de $M$. curema propuestos en este estudio (diciembreenero, marzo-abril y julio-septiembre), coinciden con los periodos de reproducción reportados por Alvarez-Lajonchere (1982) en Cuba, (junio-agosto y noviembre- 
enero), así como los mencionados por Maia y Vilela (1980) en Brasil (marzo y agosto); Rojas (1972) y Edimar (1973) en Venezuela (julio-agosto); Oren (1982) en el Golfo de México (abril-mayo); Anderson (1957) en Florida (marzo-abril); y por IbañezAguirre et al. (1995) en Veracruz (febrero a mayo). En este sentido, varios autores han reportado una reproducción continua y generalmente con dos desoves al año. De hecho, se ha reportado que en las especies de peces correspondientes a la zona subtropical y tropical, el periodo de reproducción es más prolongado, con desoves parciales o con eventos reproductivo que duran todo el año (Arellano-Martínez, 2001).

Anderson (1957) y Marin et al. (2003) reportaron que la talla de primera madurez para M. curema es a los $200 \mathrm{~mm}$ (Estados Unidos) y $240 \mathrm{~mm}$ (Venezuela). De acuerdo con lo anterior y los resultados obtenidos en el presente estudio, se considera que a los $160 \mathrm{~mm}$ de longitud patrón, inicia la maduración gonádica para esta población, abandonan el sistema con el objetivo de madurar y reproducirse en aguas oceánicas. En este sentido, Ibáñez-Aguirre et al. (1993) y Marin et al. (2003) reportan que los adultos de esta especie, migran al mar para madurar sexualmente y realizar su reproducción. Además, se debe considerar que la especie pertenece a una familia que se caracteriza por realizar migraciones de cierta importancia hacia los estuarios y lagunas costeras con fines no reproductivos (Vardiell-Cubedo et al., 2007). 


\section{LITERATURA CITADA}

Allen, T., M. Jimenez, B. Marquez \& Y. Figueroa. 2007. Ictiofauna de tres praderas de Thalassia testudinum de la costa norte del Golfo de Santa Fe, estado de Sucre, Venezuela. Bol. Inst. Oceanogr. Venezuela, 46 (1):67-78

Alvarez, L.S. 1976. Contribución al estudio del ciclo de vida de Mugil curema Valenciennes in Cuvier et Valenciennes, 1836 (Pises: Mugilidae). Investigaciones Marinas. 28:130.

Alvarez-Lajonchere, L. 1982. The fecundity of mullet (Pises, Mugilidae) from Cuban waters. Journal of. Fish Biology, 21:607-613.

Anderson, W.W. 1957. Early development, spawning, growth, and occurrence of the silver mullet (Mugil curema) along the south Atlantic coast of the United States. Fishery Bulletin of the fish and wildlife service, 57(119):397-414.

Arrington, D.A \& k.O. Winemiller. 2003. Diel changeover in sandbank fish assemblages in a neotropical floodplain river. Journal of Fish Biology, 63:442-459.

Ayala-Pérez, L.A., J. Ramos-Miranda, M. Tapia-García, I.H. Salgado-Ugarte \& G. Miranda. 2006. Distribution, Abundance and population parameters of the silver perch Bairdiella chrysoura (Lacepede, 1802) (Pisces: Scianidae) in Terminos Lagoon, Campeche, Mexico. Thalassas, 22(1):9-18

Beckman, D.W., A.L. Stanley, J.H. Render. \& C.A. Wilson. 1990. Age and growth of black drum in Louisiana USA water of the Gulf of Mexico. Transactions of the American Fisheries Society, 119:537-544.

Begon, M., C.R. Townsend. \& J.L. Harper. 1999. Ecology. From individuals to ecosystems. 4th Ed. Blackwell, Oxford.

Blaber, S.M.J. 2002. Fish in hot water: the challenges facing fish and fisheries research in tropical estuaries. Journal of Fish Biology, 61:1-20.

Blanck, A. \& N. Lamouroux. 2007. Large-scale intraspecific variation in life history traits of European freshwater fish. Journal of Biogeography, 34 (5):862-875.

Brothers, E.B. 1987. Methodological approaches to the examination o otoliths in aging studies, 319-330 pp. Summerfelt R.C. \& G.E. Hall. 1987. Age and Growth of fish. lowa State University Press, Ames. 
Brown-Peterson, N.J. \& J.R. Warren. 2001. The reproductive biology of spotted seatrout, Cynoscion nebulosus, along the Mississippi gulf coast. Gulf of Mexico Science, 1:61-73.

Cabrera-Neri. 2002. Uso del mocroondas convencional para el horneado de otolitos del robalo prieto (Centropomus nigrescens). Ciencia y Mar, 33-36.

Campana, S.E. 2001. Accuracy, precision and quality control in age determination, including a review of the use and abuse of age validation methods. Journal of Fish Biology, 59:197-242.

Castillo- Rivera, M. 1995. Aspectos ecológicos de la ictiofauna de la laguna de Pueblo Viejo, Veracruz. Tesis de Maestría en Ciencias (Biología), Facultad de Ciencias, UNAM. México $96 \mathrm{p}$.

Castillo-Rivera, M. \& R. Zarate-Hernández. 2001. Patrones espacio-temporales de la abundancia de peces en la laguna de Pueblo Viejo, Veracruz. Hidrobiológica, 11 (1):75-84.

Castillo-Rivera, M., J.A. Zavala-Hurtado \& R. Zárate. 2003a. Exploration of spatial and temporal patterns of fish diversity and composition in a tropical estuarine system of Mexico. Reviews in Fish Biology and Fisheries, 12: 167-177.

Castillo-Rivera, M., R. Zárate \& L. Sanvicente-Añorve. 2003b. Patrones de la diversidad de peces en la laguna de Pueblo Viejo, Veracruz, México. Hidrobiológica, 13 (4): 289-298.

Castillo-Rivera, M., S. Ortiz-Burgos \& R. Zárate. 2005. Variación nictímera y estacional de la abundancia, riqueza y species dominantes de peces, en un ambiente salobre de sustrato blando. Hidrobiológica, 15:227-238.

Castillo-Rivera, M., J.A. Zavala-Hurtado, S. Ortiz-Burgos \& R. Zárate. 2010. Diel and seasonal variability in the fish community structure of a mud-bottom estuarine habitat in the Gulf of Mexico. Marine Ecology, 1-10.

CONAPESCA. 2003. Anuario Estadístico de Pesca. SAGARPA-CONAPESCA.

Curtis, J.M.R. \& A.C.J. Vincent. 2006. Life history of an unusual marine fish: survival, growth and movement patterns of Hippocampus guttulatus Cuvier 1829. Journal of Fish Biology, 68 (3):707-733.

Edimar, C.L.A.1973. Algunos aspectos de la biología de la lisa Mugil curema en aguas hipersalinas del Nororiente de Venezuela, Mem. Soc. Scienc. Nat. Contrib. $51: 223-238$. 
Espino-Barr, E., E.G. Cabral-Solis, M. Gallardo-Cabello \& A. L. Ibáñez-Aguirre. 2005. Age determination of Mugil curema Valencines, 1836 (Pisces:Mugilidae) in the Cuyutlán Lagoon, Colima, México. International Journal of Zoological Research, 1 (1): 21-25.

Fernández-Delgado, C. 2006. Life-history patterns of the mosquito-fish, Gambusia affinis, in the estuary of the Guadalquivir river of south-west Spain. Freshwater Biology, 22: 395-404.

Ferrer-Montaño, O.J. 1994. Recruitment of White Mullet in Lake Maracaibo, Venezuela. North American Journal of Fisheries Management, 14: 516-521.

Franco, L. \& K.M.B. Bashirullah. 1992. Alimentación de la lisa (Mugil curema) del Golfo de Cariaco-Estado Suche, Venzuela. Zootecnia Tropical, 10(2): 219-238.

Fonseca, V.F. \& H.N. Cabral. 2007. Are fish early growth and condition patterns related to life-history strategies? Reviews in Fish Biology and Fisheries, 17 (4):545564.

Gaelzer, L.R. \& I. R. Zalmon. 2008. Diel variation of fish community in sandy beaches of Southeastern Brazil. Brazilian Journal of Oceanography, 56 (1): 23-39.

Gómez Márquez J.L. 1994. Métodos para determinar la edad de los organismos acuáticos. UNAM, México.

Guevara, E., A.J. Sánchez, C. Rosas, M. Mascaró \& R. Brito. 2007. Asociación trófica de peces distribuidos en Vegetación acuática sumergida en Laguna de Terminos, Sur del Golfo de México. Universidad y Ciencia, 23 (2):151-166.

Gulllan, J. A. \& A.A. Rosemberg. 1992. Examen de los metodos que se basan en la talla para evaluar las poblaciones de peces. Grupo de Evaluación de Recursos renovables. Imperial Gallage \& Prince. Reino Unido FAO.Documento técnico de pesca 15pp

Hedges, K. J., S.A. Ludsin \& B.J. Fryer. 2004. Effects of ethanol preservation on otolith microchemistry. Journal of Fish Biology, 64:923-937.

Helfman, G.S. 1993. Fish behaviour by day, night and twilight, 479-512 pp. In: T.J. Pitcher (Ed.),Behaviur of Teleost Fishes, $2^{\text {nd }}$ Ed. Chapman and Hall. London.

Ibáñez-Aguirre A.L., M. Gallardo-Cabello \& P. Sánchez Rueda. 1995. Estimación de la edad de la lisa Mugilcephdlus y la lebrancha M. curema por métodos indirectos. Hidrobiológica, 5 (1-2): 105-111. 
Ibáñez-Aguirre, A.L. 2004. Impact of the timing of stocking on growth and allometric index in aquaculture based fisheries. Fisheries Management and Ecology, 11 (2) 81-87.

Ibáñez-Aguirre, A.L. \& J. Lleonart. 1996. Relative growth and comparative morphometrics of Mugil cephalus L. and M. curema V. in the Gulf of Mexico. Scientia Marina, 60 (2-3): 361-368.

Ibáñez-Aguirre, A.L., M. Gallardo-Cabello \& X. Chiappa-Carrara. 1999. Growth analysis of striped mullet, Mugil cephalus, and white mullet, M. curema (Pisces: Mugilidae) in the Gulf of Mexico. Fishery Bulletin, 97 (4): 861-872.

Ibañez- Aguirre, A.L.; E. Cabral-Solis, M. Gallardo-Cabello \& E. Espino-Barr.2005. Age determination of Mugil curema Valenciennes, 1836 (Pisces: Mugilidae) in the Cuyutlán Lagoon, Colima, México. International Journal of Zoological Research $1(1): 21-25$.

Ibáñez-Aguirre, A.L.; E. Cabral-Solis, M. Gallardo-Cabello \& E. Espino-Barr. 2006. Comparative morphometrics of two populations of Mugil curema (Pisces: Mugilidae) on the Atlantic and Mexican Pacific coasts. Scientia Marina, 70 (1):139145.

Jaureguizar, A.J., R. Menni, R. Guerrero \& C. Lasca. 2004. Environmental factors structuring fish communities of the Río de la Plata estuary. Fisheries Research, 66:195-211

Jumars, P.A. 1993. Concepts in Biological Oceanography an interdisciplinary primer. Oxford University Press, New York, Oxford.

Kupschus, S. \& D. Tremain. 2001. Associations between fish assemblages and environmental factors in nearshore habitats of subtropical estuary. Journal of Fish Biology, 58: 1383-1403.

Krebs, C. J.1985. Ecología: Estudio de la Distribución y la Abundancia. Harla, México

Laevastu, T.1980. Manual de Métodos de Biología Pesquera. Acribia.

Lipcius, R.N. \& C.B. Subrahmanyam. 1986. Temporal factors influencing killifish abundance and recruitment in Gulf of México salt marshes. Estuarine, Coastal and Shelf Science, 22:101-114.

Lai, V. F. Galluci, D. R. Gunderson. \& R. F. Donnelly. 1996. Age determination in Fisheries: Methods and Apliccations to stock assessment, 82-155 pp. In: V.F., 
Gallucci, S. B. Saila D. J. Gustafson \& B. J. Rothschild. Quantitative methods and applications for small-scale fisheries.

Lombarte, A. \& J. Lleonart. 1993. Otolith size changes related with body growth, habitat depth and temperature. Environmental Biology of Fishes, 37:297-306

López-Olmos, J.R. 2000. Edad, crecimiento y fechas de nacimiento de juveniles de Lisa Mugil curema (Pisces: Mugilidae) en el estero El Conchalito, La Paz, Baja California Sur, México. Tesis de Maestría. 51 p.

Lubbers, L., W.R. Boynton \& W.M. Kemp. 1990. Variations in structure of estuarine fish communities in relation to abundance of submersed vascular plants. Marine Ecology Progress Series, 65:1-14.

McMahon, T.A. \& J.T. Bonner. 1986. Tamaño y vida. Editorial Labrador. España.

Maia R. C. \& I. Vilela do Nascimento. 1980. Reproduction of the white mullet Mugil curema Valenciennes, 1863, in estuarine waters of Pernambuco, Brazil. First Brazilian Symposium of Aquaculture, 205-212.

Marin B.J.E. \& J.J. Dodson. 2000. Age, growth and fecundity of the silver mullet, Mugil curema (Pisces: Mugilidae), in coastal areas of Northeastern Venezuela. Revista de Biología Tropical, 48 (2-3):389-398.

Marin, E.B.J.; D. Bussiere. \& J.J. Dodson. 2003. Reproduction and recruitment of white mullet (Mugil curema) to a tropical lagoon (Margarita Island, Venezuela) as revealed by otolith microstructure. Fishery Bulletin, 101 (4):809-821.

Mascareñas-Osorio, I., O. Aburto-Oropeza \& E.F. Balart. 2003. Otolitos de peces de arrecife del Golfo de California. Centro de Investigaciones Biologicas del Noroeste, S.C.

Martínez-Pérez, J.A., M.M. Chávez- Arteaga., J.L. Tello-Musi \& A.A. Morales-Aranda. Utilización de otolitos como herramienta en la determinación de especies. Revista de zoología, 18:13-18.

Meléndez-Galicia, C.* \& A. C. Romero-Acosta.2010. Evaluación biológico pesquera de la lisa Mugil curema,en la costa de Michoacán. Ciencia Pesquera, 18(1): 67-77.

Miranda-Marure, M. E., J. A. Martínez-Pérez. \& N. J. Brown-Peterson. 2004 Reproductive biology of the opossum pipefish, microphis Brachyurus lineatus, in tecolutla estuary, Veracruz, Mexico. Gulf and Caribbean Research,16:101-108. 
Moore, R. H. 1974. General ecology, distribution and relative abundance of Mugil cephalus and Mugil curema on the south Texas coast. Contributions in Marine. Science, 18: 241-255.

Morales-Nin B.1991. Determinación del crecimiento de peces óseos en base a la microestructura de los otolitos. FAO.

Moyle, P.B. \& J.J. Cech, Jr. 2004. Fishes: An Introduction to Ichthyology, 5th Ed.Prentice-Hall, Upper Saddle River, New Jersey.

Muhlia-Almazán, A., A. Muhlia-Melo \& G. Alcaraz. 2003. Responses to temperature and salinity by White Mullet Mugil curema: possible explanation for the population decrease in Baja California Sur. Marine and Freshwater Behaviour and Physiology, $36(3): 177-185$.

Ortiz-Burgos, G.S. 2005. Estructura de la comunidad de peces en un ambiente con vegetación sumergida de una laguna costera tropical. Tesis de Maestría en Ciencias (Biología). UAM. México.105 p.

Pérez-García, M.A. \& A.L. Ibañez-Aguirre. 1992. Morfometría de los peces Mugil cephalus y Mugil curema (Mugiliformes: Mugilidae) en Veracruz, México. Revista de Biología Tropical, 40 (3): 335-339.

Quignard, J.P. \& Farrugio, H. 1981. Age and growth of grey mullet. In: O.H. Oren (ed.), Aquaculture of Grey Mullets. Combridge University Press, Cambridge.

Quiñonez-Velázquez, C \& J. A. Mendoza-Guevara. 2009. Abundancia relativa, estructura de tallas y relación longitud-peso de juveniles de lisa Mugil curema en el estero El Conchalito, La Paz, BCS, México. Ciencia Pesquera, 17 (1):37:46.

Quiñonez-Velázquez, C., R. Alvarado-Castillo \& R. Félix-Uraga. 2002. Relacion entre el crecimiento individual y la abundancia de la población de la sardina del Pácifico Sardinops Caeruleus en Isla de Cedros, Baja California, México. Revista de Biología Marina y Oceanografía, 37 (1):1-8.

Rocha-Olivares, A., V.M. Gómez-Muñoz. 1993. Validación del uso de otolitos para determinar la edad del huachinango del Pacifico Lutjanus peru (Perciformes: Lutjanidae), en la Bahía de la Paz y aguas adyacentes, B.C.S., México. Ciencias Marinas, 19(3):321-331.

Rocha, M.L.C.F, W.S. Fernandez \& A.M. Paiva-Filho. 2010. Spatial and temporal diastribution of fish in Palmas Bay, Ubatuba, Brazil. Brazilian Journal of Oceanography, 58(1):31-43. 
Ross, S.W. 2003.The relative value of different estuarine nursery areas in North Carolina for transient juvenile marine fishes. Fishery Bulletin, 101:384-404.

Ramos-Jilberto, R. 1995. Alometria y reproducción de zooplanctontes herbívoros. Revista Chilena de Historia Natural, 68:477-488.

Richards, C. E \& M. Castagna. 1976. Distribution, Growth, and Predation of Juvenile White Mullet (Mugil curema) in Oceanside Waters of Virginia's Eastern Shore. Chesapeake Science, 17 (4): 308-309.

Ricker, W.E. 1975. Computation and interpretation of biological statistics of fish population. Bulletin on the fisheries research board of Canada. Department of the Environment fisheries and marine service. $382 \mathrm{pp}$

Rivera-Bernal, J. 1981. Contribución al estudio biológico de la Lebrancha Mugil curema (Valenciennes 1836) con fines de explotación piscícola en la Laguna de Pueblo Viejo, Veracruz, México. Universidad Autónoma de Nuevo León. Tesis Profesional. $56 \mathrm{p}$.

Rozas, L.P. \& W.E. Odum. 1988. Occupation of submerged vegetation by fishes: testing the roles of food and refuge. Oecologia, 77:101-106.

Salgado-Ugarte, I.H., M. Shimizu. \& T. Taniuchi. 1993. Exploring the shape of univariate data using kernel density estimators. Stata Technical Bulletin, 16:8-19.

Salgado-Ugarte, I.H., M. Shimizu. \& T. Taniuchi. 1995a. ASH, Warping, and kernel density estimation for univariate data. Stata Technical Bulletin, 26:23-31.

Salgado-Ugarte, I.H., M. Shimizu. \& T. Taniuchi. 1995b. Practical rules for bandwidth selection in univariate density estimation. Stata Technical Bulletin, 27:5-19.

Salgado Ugarte, I.H. 2005. Métodos Actualizados para Análisis de Datos BiológicoPesqueros. UNAM, México.

Scott Baker, Jr. and C. A. Wilson. 2001. Use of bomb radiocarbon to validate otolith section of red snapper Lutjanus campechanus from the northern Gulf of Mexico, Limnology and Oceanography, 46(7):1819-1824.

Sánchez-Rueda, P. 2002. Stomach content analysis of Mugil cephalus and Mugil curema (Mugiliformes: Mugilidae) with emphasis on diatoms in the Tamiahua Lagoon, México. Revista de Biología Tropical, 50 (1): 245-252.

Sánchez-Rueda, P., I. González-Mar; A.L. Ibáñez-Aguirre \& A. Márquez-García. 1997. Sedimento en el contenido estomacal de Mugil cephalus y Mugil curema 
(Mugiliformes: Mugilidae) en Laguna de Tamiahua, México. Revista de Biología Tropical, 45 (3): 1163-1166.

Solano-Fernández, M. 2007. Determinacion de edad y crecimiento del dorado Coryphaona hippurus (Linnaeus, 1758) en el Pacífico Sur mexicano. Tesis de Licenciatura en Biologia Marina. UMAR. Oaxaca. 71 p.

Solomon, F. N. \& I. W. Rammarine. 2007. Reproductive biology of white mullet, Mugil curema (Valenciennes) in the Southern Caribbean. Fisheries Research, 88:133138.

Spiegel, M.R., J. Schiller \& R.A. Srinivasan. 2003. Probabilidad y Estadística. Segunda edición. Mc Graw Hill

Stearns, S.C. 1992. The Evolution of Life Histories. Oxford University Press, Oxford.

Stuardo J. \& C. Valdovinos. 1989. Estuarios y lagunas costeras: ecosistemas importantes del Chile central. Ambiente y Desarrollo, 5 (1): 107-115.

Toledo, J., R. Guzmán \& G. Gómez. 1997.Contribución al conocimiento de la Lisa, Mugil curema (valenciennes, 1836) en la ciénaga de Los Olivitos, estado Zulia. I. Estructura de tallas y madurez sexual. Zootecnia Tropical, 15(1):81-90.

Torres-Orozco R. 1994. Los Peces. 269-304 pp. In: G. De la Lanza Espino \& C. Cáceres Martínez (eds). Lagunas Costeras y el Litoral Mexicano. $1^{\text {a }}$ ed,. Universidad Autónoma de Baja California Sur, UNAM.

Underwood, A.J. 1981. Techniques of analysis of variance in experimental marine biology and ecology. Oceanography and Marine Biology Annual Review 19:513605.

Unsworth, R.K.F., S.L. Garrard, P. Salinas De León, L.C. Cullen, D.J. Smith, K. A. Sloman \& J.J. Bell. 2009. Structuring of Indo-Pacific fish assemblages along the mangrove-seagrass continuum. Aquatic Biology, 5:85-95.

Verdiell-Cubedo, D., Egea-Serrano, A., Oliva-Paterna, F. J. \& M. Torralva. 2007. Biologia trofica de los juveniles del género Liza (Pisces:Mugilidae) en la laguna costera del Mar Menor (SE Península lbérica). Limnetica, 26 (1):67-73.

Vieira J.P. 1991. Juvenile Mullets (Pisces: Mugilidae) in the Estuary of Lagoa dos Patos, RS, Brazil. Copeia, 1991(2): 409-418

Wealthrley, A.H. 1987. The biology of fish growth. Academic Press. 
Waggy, G.L., N.J. Brown-Peterson. \& M.S. Peterson. 2006. Evaluation of the reproductive life history of the Sciaenidae in the Gulf of Mexico and Caribbean Sea:"Greater" versus "Lesser" Strategies? Proceedings of the Gulf and Caribbean Fisheries Institute, 57:263-282.

White, M.L. \& M.E. Chittenden. 1977. Age determination, reproduction, and population dynamics of the Atlantic croaker, Micropogonias undulatus. Fisheries Bulletin 75:109-123.

Wootton R. J. 1992. Fish Ecology. Blackie, Glasgow and London.

Zar, J. 1996. Bioestatistical Analysis. $3^{\mathrm{a}}$ Ed. Prentice Hall. Estados Unidos de América.

Zar, J. 1999. Bioestatistical Analysis. $4^{a}$ Ed. Prentice Hall. Estados Unidos de América.

Zarate-Hernández, R. 2003. Variación nictímera y estacional de la diversidad y composición de especies de peces en la laguna de pueblo, viejo, Veracruz. Tesis de Maestría en Ciencias (Biología). UAM. México. 86 p.

Ziegler, P.E., J.M. Lyle., M. Haddon \& G.P. Ewing. 2007. Rapid changes in life-history characteristics of a long-lived temperate reef fish. Marine \& Freshwater Research, 58 (12):1096-1107. 
